\title{
Visually Evoked 3-5 Hz Membrane Potential Oscillations Reduce the Responsiveness of Visual Cortex Neurons in Awake Behaving Mice
}

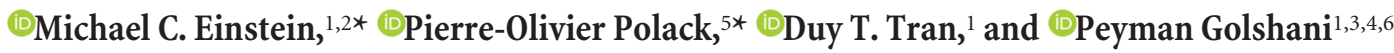 \\ ${ }^{1}$ Department of Neurology and Psychiatry, David Geffen School of Medicine, ${ }^{2}$ Neuroscience Interdepartmental Program, ${ }^{3}$ Integrative Center for Learning \\ and Memory, and ${ }^{4}$ Intellectual and Developmental Disability Research Center, University of California-Los Angeles, Los Angeles, California 90095, ${ }^{5}$ Center \\ for Molecular and Behavioral Neuroscience, Rutgers, State University of New Jersey, Newark, New Jersey 07102, and ${ }^{6}$ West Los Angeles Veterans Affairs \\ Medical Center, Los Angeles, California 90073
}

Low-frequency membrane potential $\left(V_{\mathrm{m}}\right)$ oscillations were once thought to only occur in sleeping and anesthetized states. Recently, low-frequency $V_{\mathrm{m}}$ oscillations have been described in inactive awake animals, but it is unclear whether they shape sensory processing in neurons and whether they occur during active awake behavioral states. To answer these questions, we performed two-photon guided whole-cell $V_{\mathrm{m}}$ recordings from primary visual cortex layer $2 / 3$ excitatory and inhibitory neurons in awake mice during passive visual stimulation and performance of visual and auditory discrimination tasks. We recorded stereotyped $3-5 \mathrm{~Hz} V_{\mathrm{m}}$ oscillations where the $V_{\mathrm{m}}$ baseline hyperpolarized as the $V_{\mathrm{m}}$ underwent high amplitude rhythmic fluctuations lasting 1-2 s in duration. When 3-5 $\mathrm{Hz} V_{\mathrm{m}}$ oscillations coincided with visual cues, excitatory neuron responses to preferred cues were significantly reduced. Despite this disruption to sensory processing, visual cues were critical for evoking 3-5 $\mathrm{Hz} V_{\mathrm{m}}$ oscillations when animals performed discrimination tasks and passively viewed drifting grating stimuli. Using pupillometry and animal locomotive speed as indicators of arousal, we found that $3-5 \mathrm{~Hz}$ oscillations were not restricted to unaroused states and that they occurred equally in aroused and unaroused states. Therefore, lowfrequency $V_{\mathrm{m}}$ oscillations play a role in shaping sensory processing in visual cortical neurons, even during active wakefulness and decision making.

Key words: behavior; cortex; membrane potential; oscillation

Significance Statement

A neuron's membrane potential $\left(V_{\mathrm{m}}\right)$ strongly shapes how information is processed in sensory cortices of awake animals. Yet, very little is known about how low-frequency $V_{\mathrm{m}}$ oscillations influence sensory processing and whether they occur in aroused awake animals. By performing two-photon guided whole-cell recordings from layer $2 / 3$ excitatory and inhibitory neurons in the visual cortex of awake behaving animals, we found visually evoked stereotyped $3-5 \mathrm{~Hz} V_{\mathrm{m}}$ oscillations that disrupt excitatory responsiveness to visual stimuli. Moreover, these oscillations occurred when animals were in high and low arousal states as measured by animal speed and pupillometry. These findings show, for the first time, that low-frequency $V_{\mathrm{m}}$ oscillations can significantly modulate sensory signal processing, even in awake active animals.

\section{Introduction}

Low-frequency $(<15 \mathrm{~Hz})$ membrane potential $\left(V_{\mathrm{m}}\right)$ oscillations were first described during slow-wave sleep and anesthetized

\footnotetext{
Received Dec. 13, 2016; revised March 28, 2017; accepted April 1, 2017.

Author contributions: M.C.E., P.-0.P., and P.G. designed research; M.C.E., P.-0.P., and D.T.T. performed research; M.C.E. analyzed data; M.C.E. wrote the paper.

This work was supported by National Institutes of Health Grants 1R01-MH101198, R01-MH105427-A1, and R01-NS090930. M.C.E. was supported by National Research Service Award F31EY025185-02. We thank all the members of the P.G. laboratory for their support and insightful comments in reviewing the data and manuscript. The authors declare no competing financial interests.

${ }^{*}$ M.C.E. and P.-0.P. contributed equally to this study.
}

states but were found to be absent in the $V_{\mathrm{m}}$ of awake animals (Woody and Gruen, 1978; Steriade et al., 1993; Destexhe et al., 2003). Over time, studies have shown that strong low-frequency $V_{\mathrm{m}}$ fluctuations exist in the cortical neurons of awake animals, but only when animals are immobile (Wiest and Nicolelis, 2003; Crochet and Petersen, 2006; Poulet and Petersen, 2008; Bennett

Correspondence should be addressed to Dr. Peyman Golshani, 700 Westwood Plaza, Center for Health Sciences B2-414, Los Angeles, CA 90095. E-mail: pgolshani@mednet.ucla.edu. DOI:10.1523/JNEUROSCI.3868-16.2017

Copyright $\odot 2017$ the authors $\quad 0270-6474 / 17 / 375084-15 \$ 15.00 / 0$ 
et al., 2013; Polack et al., 2013; Schneider et al., 2014; Zhou et al., 2014), unaroused (Reimer et al., 2014; McGinley et al., 2015; Vinck et al., 2015) (as indicated by pupillometry), or unstimulated (Tan et al., 2014). Yet, it is still unclear whether lowfrequency $V_{\mathrm{m}}$ oscillations play a functional role in processing sensory signals in awake animals and whether they are exclusive to quiescent periods associated with low arousal.

We identified stereotyped $3-5 \mathrm{~Hz} V_{\mathrm{m}}$ oscillations occurring in primary visual cortex (V1) layer 2/3 (L2/3) neurons of awake mice placed in a wide range of behavioral and sensory contexts. During these 3-5 Hz $V_{\mathrm{m}}$ oscillations, neurons' baseline $V_{\mathrm{m}}$ became hyperpolarized and displayed high-amplitude $(10-20 \mathrm{mV})$ fluctuations that lasted only $1-2 \mathrm{~s}$ in length. Functionally, $3-5 \mathrm{~Hz}$ $V_{\mathrm{m}}$ oscillations significantly reduced the responsiveness of excitatory neurons, whereas inhibitory parvalbumin- and somatostatinpositive $\left(\mathrm{PV}^{+}, \mathrm{SOM}^{+}\right)$neurons fired rhythmically at the peak of each oscillatory cycle. Even though $3-5 \mathrm{~Hz} V_{\mathrm{m}}$ oscillations disrupted visual processing, visual stimulation was critical for eliciting 3-5 Hz $V_{\mathrm{m}}$ oscillations when animals actively discriminated and passively viewed drifting grating visual stimuli. Moreover, we found that these low-frequency $V_{\mathrm{m}}$ oscillations were not exclusive to unaroused behavioral states and occurred at equal rates in aroused and unaroused animals. As a result, our findings show a distinct role for low-frequency $V_{\mathrm{m}}$ oscillations in aroused and unaroused animals, challenging the hypothesis that low-frequency $V_{\mathrm{m}}$ oscillations are restricted to unaroused behavioral states.

\section{Materials and Methods}

Surgery. All experimental procedures were approved by the University of California, Los Angeles Office for Animal Research Oversight and by the Chancellor's Animal Research Committees. Adult (2-12 months old) male and female C57BL/6J, SOM-Cre (JAX\#013044) × Ai9 (JAX\#007909), and PV-Cre (JAX\#008069) $\times$ Ai9 mice were anesthetized with isoflurane (3\%-5\% induction, $1.5 \%$ maintenance) 10 min after injection of a systemic analgesic (carprofen, $5 \mathrm{mg}$ per $\mathrm{kg}$ of body weight) and placed in a stereotaxic frame. Mice were kept at $37^{\circ} \mathrm{C}$ at all times using a feedbackcontrolled heating pad. Pressure points and incision sites were injected with lidocaine $(2 \%)$, and eyes were protected from desiccation using artificial tear ointment. The skin above the skull was incised, a custommade lightweight metal head holder was implanted on the skull using Vetbond (3M) and a recording chamber was built using dental cement (Ortho-Jet, Lang). Mice had a recovery period from surgery of $5 \mathrm{~d}$, during which they were administered amoxicillin $(0.25 \mathrm{mg} / \mathrm{ml}$ in drinking water through the water supply). After the recovery period, mice were habituated to head fixation on the spherical treadmill. On the day of the recording, mice were anesthetized with isoflurane. To fix the ground wire, a small craniotomy ( $0.5 \mathrm{~mm}$ diameter) was made above the right cerebellum and a silver wire was implanted at the surface of the craniotomy and fixed with dental cement. A circular craniotomy (diameter $=3 \mathrm{~mm}$ ) was performed above V1 and a 3-mm-diameter coverslip drilled with a 500$\mu \mathrm{m}$-diameter hole was placed over the dura, such that the coverslip fit entirely in the craniotomy and was flush with the skull surface. The coverslip was kept in place using Vetbond and dental cement, and the recording chamber was filled with cortex buffer containing $135 \mathrm{~mm}$ $\mathrm{NaCl}, 5 \mathrm{~mm} \mathrm{KCl}, 5 \mathrm{~mm}$ HEPES, $1.8 \mathrm{~mm} \mathrm{CaCl}_{2}$, and $1 \mathrm{~mm} \mathrm{MgCl}_{2}$. The head-bar was fixed to a post, and the mouse was placed on the spherical treadmill to recover from anesthesia. The spherical treadmill was a ball floating on small cushion of air allowing for full 2D movement. Ball motions were tracked with a custom-made tracker that reported $x$ and $y$ speeds at $100 \mathrm{~Hz}$. All recordings were performed at least $2 \mathrm{~h}$ after the end of anesthesia, when the mouse was alert and could actively participate in the behavioral task.

Electrophysiological recordings. Long-tapered micropipettes made of borosilicate glass $(1.5 \mathrm{~mm}$ outer diameter, $0.86 \mathrm{~mm}$ inner diameter, Sutter Instruments) were pulled on P-1000 pipette puller (Sutter Instruments) to a resistance of 3-7 M $\Omega$, and filled with an internal solution containing $115 \mathrm{~mm}$ potassium gluconate, $20 \mathrm{~mm} \mathrm{KCl}, 10 \mathrm{~mm}$ HEPES, 10 mu phosphocreatine, $14 \mathrm{~mm}$ ATP-Mg, $0.3 \mathrm{~mm}$ GTP, and 0.01-0.05 mM Alexa-594 (for experiments with C57BL/6 mice) or Alexa-488 (for interneuron recordings). Pipettes were lowered into the brain under twophoton imaging guidance performed with a MOM microscope (Sutter Instruments) using a Ti-Sapphire Ultra-2 laser (Coherent) at $800 \mathrm{~nm}$ and a $40 \times 0.8$ NA Olympus water-immersion objective. Images were acquired using Scanimage 3.2 software (Pologruto et al., 2003). Whole-cell current-clamp recordings were performed using the bridge mode of an Axoclamp 2A amplifier (Molecular Devices), then further amplified and low-pass filtered at $5 \mathrm{kHz}$ using a Warner Instruments amplifier (LPF 202A). Recordings typically lasted $30 \mathrm{~min}$ (range 5-60 min). Recordings or parts of recordings with unstable membrane potential and/or action potentials $<35 \mathrm{mV}$ were excluded from analysis. Electrocorticogram (ECoG) recordings were performed with an alternating/direct current differential amplifier (model 3000, A-M System) and bandpass filtered at $0.1-3000 \mathrm{~Hz}$. Analog signals were digitized at $12,415 \mathrm{~Hz}$ with WinEDR (Strathclyde University) using a NIDAQ card (National Instruments). To ensure synchrony between physiological signals and behavioral epochs, signals relevant to the behavioral task (licking, water delivery, visual/auditory cue characteristics and timing, locomotion, and pupil size) were recorded in tandem with electrophysiological signals by the same NIDAQ card. We recorded 40 excitatory, $6 \mathrm{PV}^{+}$, and $7 \mathrm{SOM}^{+}$neurons from 29,5 , and 6 untrained mice, respectively, in separate experiments to ascertain $3-5 \mathrm{~Hz}$ oscillation activity during spontaneous behavior and passive viewing. Excitatory neurons were identified post hoc by using half-height spike widths $(>0.6 \mathrm{~ms})$ and mean evoked firing rate $(<4 \mathrm{sp} / \mathrm{s})$ to cluster units. We recorded 21 neurons from 17 trained mice in separate experiments to ascertain $3-5 \mathrm{~Hz}$ oscillation activity during visual and auditory discrimination.

Visual stimulus presentation. A $40 \mathrm{~cm}$ diagonal LCD monitor was placed in the monocular visual field of the mouse at a distance of $30 \mathrm{~cm}$, contralateral to the craniotomy. Custom-made software developed with Psychtoolbox in MATLAB (The MathWorks) was used to display drifting sine wave gratings (series of 12 orientations spaced by 30 degrees randomly permuted, temporal frequency $=2 \mathrm{~Hz}$, spatial frequency $=$ 0.04 cycle per degree, contrast $=100 \%)$. For passive viewing, the presentation of each orientation lasted 1.5 or $3 \mathrm{~s}$ and was followed by the presentation of a gray isoluminant screen for an additional 1.5 or $3 \mathrm{~s}$, respectively. The electrophysiological signal was digitized simultaneously with two analog signals coding for the spatial and temporal properties of the grating. The treadmill motion was measured every $25 \mathrm{~ms}$ (40 $\mathrm{Hz}$ ) by an optical mouse whose signal was converted into two servo pulse analog signals (front-back and left-right) using an external PIC microcontroller, and acquired simultaneously with the electrophysiological data. Importantly, the monitor was placed in the exactly the same way during the auditory discrimination task as it was placed during the visual discrimination task, and a gray screen, which was identical to that during the intertrial interval (ITI) of the visual discrimination task and isoluminant to the drifting visual cues, was displayed throughout auditory discrimination trials. As a result, the luminance conditions were identical during visual and auditory discrimination trials.

Training. C57BL/6J mice (The Jackson Laboratory) with head-bar implants were water-deprived to $90 \%$ of their body weight and acclimated to head fixation on a spherical treadmill in custom-built, soundproof training rigs. Each rig was equipped with a monitor (Dell), water dispenser with a built-in lickometer (to monitor licking, infrared beam break) (Island-Motion), an infrared camera (Microsoft), and stereo speakers (Logitech). In addition, data acquisition boards (National Instruments) were used to actuate water delivery and vacuum reward retrieval as well as monitor animal licking. Data acquisition boards and the monitor were connected to a laptop (Dell), which ran the custom-made training program (MATLAB). Once animals reached the target weight, animals were acclimated to the spherical treadmill over $3 \mathrm{~d}$ before being trained to discriminate visual stimuli or auditory. In the visual discrimination task, drifting sine-wave gratings at one orientation were paired with a water reward, and the animal was expected to lick (Go). Orthogonal drifting gratings signaled the absence of reward, and the animal was expected to withhold licking (No-Go) during these trials. In the auditory 
discrimination task, a $100 \mathrm{~dB} 5 \mathrm{kHz}$ pure tone indicated Go trials and a $100 \mathrm{~dB} 10 \mathrm{kHz}$ pure tone indicated No-Go trials.

Each trial lasted $3 \mathrm{~s}$. The visual or auditory stimulus was present for the duration of the trial. When the stimulus instructed the animal to lick, water was dispensed $2 \mathrm{~s}$ after stimulus onset. No water was dispensed in the no-lick condition. Licking was only assessed during the final second of the trial. If the animal responded correctly, the ITI was 3 s. If the animal responded incorrectly, the ITI was increased to $9.5 \mathrm{~s}$ as negative reinforcement. If the animal missed a reward, the reward was removed by vacuum at the end of the trial. Animals performed 300-500 trials daily. During the auditory task with visual cues task, visual cues identical to those used in the visual discrimination task were displayed at the same times that auditory cues were played. Visual cues did not correlate with reward in this condition.

Performance was measured using the $\mathrm{D}^{\prime}$ statistic $\left(\mathrm{D}^{\prime}=\operatorname{norminv}\right.$ (fraction trials with correct licking) - norminv(fraction trials with incorrect licking), norminv $=$ inverse of the normal cumulative distribution function), which compares the SD from chance performance during lick and no-lick trials (chance $\mathrm{D}^{\prime}=0$ ). Animals were considered experts if their sessions average $\mathrm{D}^{\prime}>1.7$ (probability of chance behavior $<0.1 \%$, Monte Carlo simulation).

Pupillometry. To record pupil size, the infrared filter and lens was removed from a webcam (Microsoft LifeCam HD-3000, $30 \mathrm{~Hz}$ frame rate) and was fitted with a $50 \mathrm{~mm}$ fixed focal length lens (Thorlabs MVL50M23). The camera was placed $\sim 0.5 \mathrm{~m}$ ipsilateral to the monitor displaying visual cues, and a generic infrared lamp was used to provide strong illumination of the eye. To read the pupil size and movements, the camera was operated by custom scripts (MATLAB) that used thresholding to isolate the pupil from the eye and measure pupil properties. The software then created scaled analog signals relaying the pupil area and position to the electrophysiology recording apparatus such that pupil measurements were acquired in sync with the electrophysiological and behavioral data. Videos were also saved for post hoc analysis as necessary. Pupil size was normalized to the maximum pupil size in pixels. To isolate pupil dilation and constricting episodes, we computed the first derivative of the filtered ( $1 \mathrm{~Hz}$ low pass filter) pupil area trace in time. Periods when the first derivative was $>0$ or $<0$ were recorded as dilation or constriction events, respectively. To remove events where constriction or dilation was negligible, events where total pupil size change was $<5 \%$ were eliminated.

Analysis. Data analysis was performed using custom routines in MATLAB. The $3-5 \mathrm{~Hz}$ oscillations were defined as stereotyped lowfrequency and high-amplitude oscillations of the $V_{\mathrm{m}}$ superimposed on a steady hyperpolarizing envelope (see examples in Figs. $1 A-C, 2 A, 3 A, 4 A$, $6 A, B, 9 A, 10 A)$. We were able to isolate the oscillations in all recorded neurons using a semiautomated method that detected candidate oscillation locations using these metrics and then gathered human input to finalize oscillation start and stop times. The beginning and end of $3-5 \mathrm{~Hz}$ $V_{\mathrm{m}}$ oscillations were defined as the start of the hyperpolarization and the time when the neuron had repolarized, respectively (for 10 detailed examples, see Fig. $1 B$ ). Our MATLAB code to detect $3-5 \mathrm{~Hz} V_{\mathrm{m}}$ oscillations is hosted at https://github.com/michaeleinstein/3-5-Hz/blob/master/ get4hzOsc.m. After semiautomated detection, the whole trace was then scanned manually to ensure that all oscillations were detected. The $V_{\mathrm{m}}$ baseline was defined as the mean of the bottom 20th percentile of the $V_{\mathrm{m}}$ distribution, and the change in $V_{\mathrm{m}}$ baseline during oscillations was defined as the baseline during the oscillation epoch minus the baseline $1 \mathrm{~s}$ before the oscillation epoch. Phase offset was obtained by calculating the difference in time between positive and negative peaks in low pass filtered $(-3 \mathrm{~dB}$ at $10 \mathrm{~Hz})$ ECoG and $V_{\mathrm{m}}$ signals measured in degrees during oscillatory epochs. To compare firing rates evoked by visual stimuli during passive viewing and behavior with and without oscillations, trials with the presence of an oscillatory epoch at any point of visual stimuli were compared with visual stimuli without any oscillations. Plots showing oscillation probability over time were created by computing the mean oscillation probability in specific time bins. During the behavioral task, the optimal visual stimulus was defined as the stimulus that had a greater mean evoked firing rate. Locomotion on/off criteria were identical to
Polack et al. (2013): locomotion onset and offset were defined when sustained treadmill was $>2 \mathrm{~cm} / \mathrm{s}$ and $<2 \mathrm{~cm} / \mathrm{s}$ for at least $1 \mathrm{~s}$, respectively.

Statistics. Unless stated otherwise, statistical significance was calculated by Wilcoxon Signed Rank Test (WSRT), Wilcoxon Rank-Sum Test (WRST), one-way ANOVA, and repeated-measures one-way ANOVA. Scale bars and shading around means represent SEM unless indicated. Wilcoxon and non-repeated-measures ANOVA tests were performed in MATLAB. Repeated-measures ANOVA tests were performed in SPSS Statistics version 21 (IBM).

\section{Results}

The 3-5 Hz $V_{\mathrm{m}}$ oscillations are highly stereotyped, synchronized, and transient network events that selectively reduce the responsiveness of excitatory neurons

We performed two-photon guided whole-cell $V_{\mathrm{m}}$ recordings from 40 excitatory V1 L2/3 neurons in head-fixed mice free to run or rest on a spherical treadmill (Fig. 1A). For each recording, ECoG activity was simultaneously acquired within the vicinity $(300-500 \mu \mathrm{m})$ of the patch-clamp pipette tip. In all our recordings, we detected distinct epochs of high amplitude $3-5 \mathrm{~Hz} V_{\mathrm{m}}$ oscillations that appeared very similar across recordings (Fig. 1). During 3-5 Hz $V_{\mathrm{m}}$ oscillations, the neuron's baseline $V_{\mathrm{m}}$ substantially hyperpolarized (Fig. $1 B, C, F$; mean change in $V_{\mathrm{m}}$ baseline $=-11.6 \mathrm{mV}, \sigma(\mathrm{SD})=4.5 \mathrm{mV})$ and displayed high amplitude (Fig. $1 B, C, G$; mean trough to peak amplitude $=17.3$ $\mathrm{mV}, \sigma=4.2 \mathrm{mV}$ ) rhythmic depolarizations (Fig. $1 B, D, E, H$; mean frequency $=4.2 \mathrm{~Hz}, \sigma=0.4 \mathrm{~Hz}$ ) that typically lasted for $1-2 \mathrm{~s}$ (Fig. $1 B, E, I$; mean duration $=1.6 \mathrm{~s} \sigma=0.38 \mathrm{~s}$ ). When we calculated the Pearson correlation coefficient comparing $3-5 \mathrm{~Hz}$ $V_{\mathrm{m}}$ oscillation to each other and a portion of the recording of equal length $4 \mathrm{~s}$ before each $3-5 \mathrm{~Hz} V_{\mathrm{m}}$ oscillation, we found that 3-5 Hz $V_{\mathrm{m}}$ oscillations were correlated to each other, but not to the periods without oscillations in single neuron examples (cell 8; WSRT, $p<0.0001$; Fig. $1 J, K$ ) and across all excitatory neurons (WSRT, $p<0.0001$; Fig. $1 L$ ). As a result, $3-5 \mathrm{~Hz} V_{\mathrm{m}}$ oscillations are stereotyped events defined by a specific frequency, oscillation amplitude, baseline hyperpolarization, and duration.

Because excitatory neurons' $V_{\mathrm{m}}$ hyperpolarized and neared threshold only during the depolarized phase of 3-5 Hz oscillations, we hypothesized that their responsiveness to visual stimuli could decrease during 3-5 Hz oscillations. So, we investigated how excitatory neurons responded when mice were presented with full-screen drifting gratings to the monocular visual field contralateral to the hemisphere of the brain where the recording was made. In the presence of $3-5 \mathrm{~Hz} V_{\mathrm{m}}$ oscillations, the response to preferred stimuli was nearly abolished $\left(2.82 \pm 0.71 \mathrm{Sp} . \mathrm{s}^{-1} \mathrm{No}\right.$ Osc. and Preferred stimulus; $0.75 \pm 0.18$ Sp.s ${ }^{-1}$ Osc. and Preferred stimulus; $n=40$ neurons; WSRT, $p=8.1 \times 10^{-5}$; Fig. $2 A, B)$. Moreover, $3-5 \mathrm{~Hz} V_{\mathrm{m}}$ oscillations dominate $V_{\mathrm{m}}$ spectral properties when $3-5 \mathrm{~Hz} V_{\mathrm{m}}$ oscillations coincide with visual cues (Fig. 2C).

To investigate whether $3-5 \mathrm{~Hz} V_{\mathrm{m}}$ oscillations were specific to excitatory neurons, we also performed two-photon guided wholecell $V_{\mathrm{m}}$ recordings from $\mathrm{PV}^{+}(n=6)$ and $\mathrm{SOM}^{+}(n=7)$ neurons in separate experiments as animals passively viewed identical drifting gratings (Fig. 3). The oscillation frequency (one-way ANOVA $p=0.81$ ), duration (one-way ANOVA, $p=0.69$ ), and baseline hyperpolarization (one-way ANOVA, $p=0.55$ ) were similar in excitatory, $\mathrm{PV}^{+}$, and $\mathrm{SOM}^{+}$neurons (Fig. $3 E, F$ ). However, $\mathrm{PV}^{+}$interneurons exhibited larger-amplitude depolarizing events (one-way ANOVA, $p=0.01$ ) than excitatory (WRST, Bonferroni-adjusted $p=0.04$ ) and $\mathrm{SOM}^{+}$(WRST, Bonferroni-adjusted $p=0.01$ ) neurons did during oscillatory 

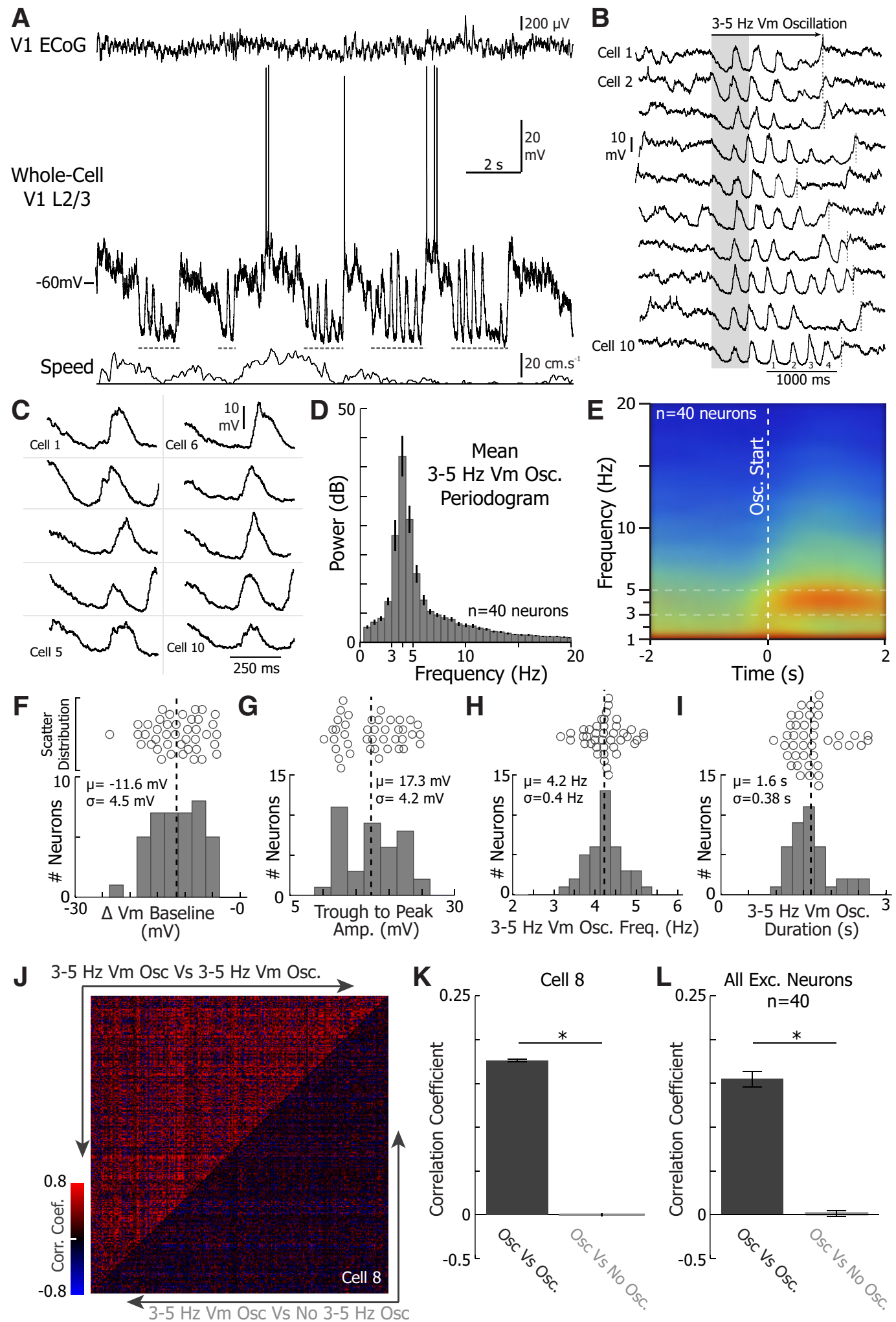

Figure 1. $\quad 3-5 \mathrm{~Hz} V_{\mathrm{m}}$ oscillations are brief stereotyped events characterized by high amplitude $3-5 \mathrm{~Hz}$ fluctuations riding on a hyperpolarized baseline $V_{\mathrm{m}} \cdot A$, Example whole-cell recording from a V1 layer 2/3 excitatory neuron during wakefulness, simultaneously recorded with the local ECoG (top) placed over V1 and the treadmill motion (locomotion, bottom). Gray dotted lines indicate times when $3-5 \mathrm{~Hz}$ oscillations were observed in the neuron's $V_{m} . B$, Example $3-5 \mathrm{~Hz} V_{m}$ oscillations from 10 neurons. The beginning and end of the $3-5 \mathrm{~Hz} V_{m}$ oscillations are indicated by the left edge of the shaded box and the dotted vertical line, respectively. The cycles are numbered on cell 10 to demonstrate the frequency of the oscillations. $\boldsymbol{C}$, Zoom up of the shaded region in $\boldsymbol{B}$. Note the hyperpolarization and the similar amplitude of the oscillation across all 10 neurons. The mean periodogram $(\boldsymbol{D})$ and spectrogram $(\boldsymbol{E})$ during $3-5 \mathrm{~Hz} V_{\mathrm{m}}$ oscillations collected from 40 neurons. Histogram of the mean change in $V_{m}$ baseline $(\boldsymbol{F})$ and histogram of the mean trough to peak amplitude during $3-5 \mathrm{~Hz} V_{\mathrm{m}}$ oscillations $(n=40$ neurons) (G). Histogram of the mean oscillation frequency $(\boldsymbol{H})$ and histogram of the mean oscillation duration $(n=40$ neurons) $(\boldsymbol{I})$. Mean $(\mu)$ and SD $(\sigma)$ are shown on each histogram. Scatter plots above each histogram further illustrate each distribution. $J$, The Pearson correlation coefficient between each $3-5 \mathrm{~Hz} V_{\mathrm{m}}$ oscillation (top left, $3-5 \mathrm{~Hz} V_{\mathrm{m}} 0 \mathrm{sc} v \mathrm{vs} 3-5 \mathrm{~Hz} V_{\mathrm{m}} 0 \mathrm{sc}$ ) and each $3-5 \mathrm{~Hz} V_{\mathrm{m}}$ 0scillation and a period of equal length $4 \mathrm{~s}$ preceding each 3-5 Hz $V_{m}$ oscillation (bottom right, $3-5 \mathrm{~Hz} V_{\mathrm{m}} 0 s \mathrm{vs} \mathrm{No} 3-5 \mathrm{~Hz} V_{\mathrm{m}} 0 \mathrm{sc}$ ) for every oscillation in one neuron (cell $8, n=2893-5 \mathrm{~Hz} V_{\mathrm{m}}$ oscillations). (Figure legend continues.) 
periods. As a result, $3-5 \mathrm{~Hz} V_{\mathrm{m}}$ oscillations are present and nearly identical in excitatory, $\mathrm{PV}^{+}$, and $\mathrm{SOM}^{+} \mathrm{V} 1 \mathrm{~L} 2 / 3$ neurons.

In contrast to excitatory neurons, $\mathrm{PV}^{+}$ and $\mathrm{SOM}^{+}$neurons tended to fire strongly at the peak of 3-5 Hz $V_{\mathrm{m}}$ oscillations (Fig. $3 B$ ). The percentage of peaks where at least one action potential was elicited was significantly lower (one-way ANOVA, $p<0.0001)$ in excitatory neurons than in $\mathrm{PV}^{+}$(WRST, Bonferroniadjusted $p=0.0001$ ) and $\mathrm{SOM}^{+}$neurons (WRST, $p=0.0008$ ). On average, the firing rate per cycle of the oscillation was also significantly lower (one-way ANOVA, $p<0.0001)$ in excitatory neurons than in $\mathrm{PV}^{+}$(WRST, Bonferroni-adjusted $p=$ 0.0001 ) and $\mathrm{SOM}^{+}$(WRST, Bonferroniadjusted $p=0.0006$ ). Correspondingly, the visually evoked firing rate in the presence and absence of 3-5 Hz $V_{\mathrm{m}}$ oscillations was not different in $\mathrm{PV}^{+}$(two-way repeated-measures ANOVA, $p=0.83$ ) and in $\mathrm{SOM}^{+}$neurons (two-way repeated-measures ANOVA, $p=0.86$ ) (Fig. 3C). The spontaneous firing rate was slightly reduced in excitatory neurons (Fig. 3D; WSRT, $p=0.034$ ), but not in $\mathrm{PV}^{+}$(Fig. 3D; WSRT, $p=0.13$ ) and $\mathrm{SOM}^{+}$(Fig. 3D; WSRT, $p=0.25$ ) neurons, during 3-5 Hz $V_{\mathrm{m}}$ oscillations

To identify whether $3-5 \mathrm{~Hz} V_{\mathrm{m}}$ oscillations were isolated to individual neurons or whether other neurons in the local network oscillated synchronously with each other, we compared the timing of the average cycle in the $V_{\mathrm{m}}$ to the local V1 ECoG trace (Fig. $4 A-C$ ). The mean phase offset between the ECoG and $V_{\mathrm{m}}$ was not different (one-way ANOVA, $p=0.28$ ) between all three cell types (mean phase offset, excitatory neurons: $-7.5^{\circ} \pm 2.2^{\circ}, \mathrm{PV}^{+}$neurons: $-12.3^{\circ} \pm 3.8^{\circ}, \mathrm{SOM}^{+}$ neurons: $-14.6^{\circ} \pm 3.1^{\circ}$; Fig. $4 C$ ). Additionally, the $V_{\mathrm{m}}$ and ECoG were significantly more correlated during $3-5 \mathrm{~Hz} V_{\mathrm{m}}$ oscillations than in the second following oscillation offset in excitatory (WSRT, $p=3.2 \mathrm{e}-8), \mathrm{PV}^{+}($WSRT, $p=0.004)$, and SOM ${ }^{+}$(WSRT, $p=5.8 \mathrm{e}-4)$ neurons (Fig. $4 D$ ). There was no difference in peak $V_{\mathrm{m}}$-ECoG correlation coefficient during oscillations in excitatory, $\mathrm{PV}^{+}$, and $\mathrm{SOM}^{+}$neurons (one-way ANOVA, $p=0.64$; Fig. 4D). These data suggest that $3-5 \mathrm{~Hz} V_{\mathrm{m}}$ oscillations occurred synchronously in L2/3 V1 neurons. Yet, only excitatory neurons showed a reduction in responsiveness to visual cues.

To understand whether $3-5 \mathrm{~Hz} V_{\mathrm{m}}$ oscillations altered the local network state, we analyzed how low- and high-frequency ECoG power varied before, during, and after 3-5 $\mathrm{Hz} V_{\mathrm{m}}$ oscillations (Fig. 4E). During 3-5 Hz $V_{\mathrm{m}}$ oscillations in all neurons,

\footnotetext{
$\leftarrow$

(Figure legend continued.) $\boldsymbol{K}$, The mean correlation coefficient between each $3-5 \mathrm{~Hz} V_{\mathrm{m}}$ oscillation and each $3-5 \mathrm{~Hz} V_{\mathrm{m}}$ 0scillation compared with the 2 s before a $3-5 \mathrm{~Hz} \mathrm{~V}_{\mathrm{m}}$ oscillation (cell 8, $n=2893-5 \mathrm{~Hz} V_{\mathrm{m}}$ oscillations; WSRT, $\left.p<0.0001\right)$. $L$, The mean correlation coefficient between each 3-5 Hz $V_{m}$ oscillation and each 3-5 Hz $V_{m}$ oscillation compared with the $2 \mathrm{~s}$ before a $3-5 \mathrm{~Hz} V_{\mathrm{m}}$ oscillation averaged across all excitatory neurons ( $n=40$ neurons; WSRT, $p<0.0001)$. Error bars indicate SEM. ${ }^{*} p<0.05$.
}

30-50 Hz ECoG power was decreased (one-way ANOVA, $p<0.0001$ ) during the oscillation compared with the $2 \mathrm{~s}$ before (WSRT, Bonferroni-adjusted $p<0.0001$ ) and after (WSRT, Bonferroni-adjusted $p=0.0001)$ the oscillatory epoch. Likewise, 3-5 Hz ECoG power increased (one-way ANOVA, $p=0.0012$ ) during the oscillation compared with before (WSRT, Bonferroniadjusted $p<0.0001$ ) and after (WSRT, Bonferroni-adjusted $p<$ $0.0001)$ the oscillatory epoch. In tandem, $3-5 \mathrm{~Hz} V_{\mathrm{m}}$ power was significantly raised (one-way ANOVA, $p<0.0001$ ) during the oscillation compared with directly before (WSRT, Bonferroni-adjusted $p<$ 0.0001 ) and after (WSRT, Bonferroni-adjusted $p<0.0001$ ) the oscillatory epoch (Fig. $4 F$ ). Therefore, $3-5 \mathrm{~Hz} V_{\mathrm{m}}$ oscillations occur during distinct periods of increased low-frequency and decreased high-frequency ECoG power and constitute a brief interruption of ongoing network dynamics.

\section{The $3-5 \mathrm{~Hz} V_{\mathrm{m}}$ oscillations are recruited by visual stimuli}

Visual stimulation, activity, arousal, and behavior have all been shown to affect the presence of low-frequency $V_{\mathrm{m}}$ fluctuations in visual cortical neurons of awake animals (Bennett et al., 2013; Polack et al., 2013; Reimer et al., 2014; Tan et al., 2014; McGinley et al., 2015; Vinck et al., 2015). To test these variables in relation to $3-5 \mathrm{~Hz} V_{\mathrm{m}}$ oscillations, we decided to investigate the $V_{\mathrm{m}}$ dynamics in animals performing visual and auditory discrimination tasks. Mice were trained to perform a visually $(n=17)$ or auditory $(n=7)$ guided $\mathrm{Go} / \mathrm{No}$-Go discrimination task before wholecell recordings (Fig. $5 A, B$ ). During the task, animals had to decide whether to lick for a water $\operatorname{drop}(\mathrm{Go})$ or withhold licking (No-Go) based on visual cues (Go stimulus: $45^{\circ}$ drifting gratings or $5 \mathrm{kHz}$ pure tone; No-Go stimulus: $135^{\circ}$ drifting gratings or 10 $\mathrm{kHz}$ pure tone; Fig. $5 \mathrm{~B}$ ). Visual or auditory stimuli were displayed 
A

excitatory

$L 2 / 3, n=40$ parvalbumin +

$\mathrm{L} 2 / 3, \mathrm{n}=6$ somatostatin +

$L 2 / 3, n=7$
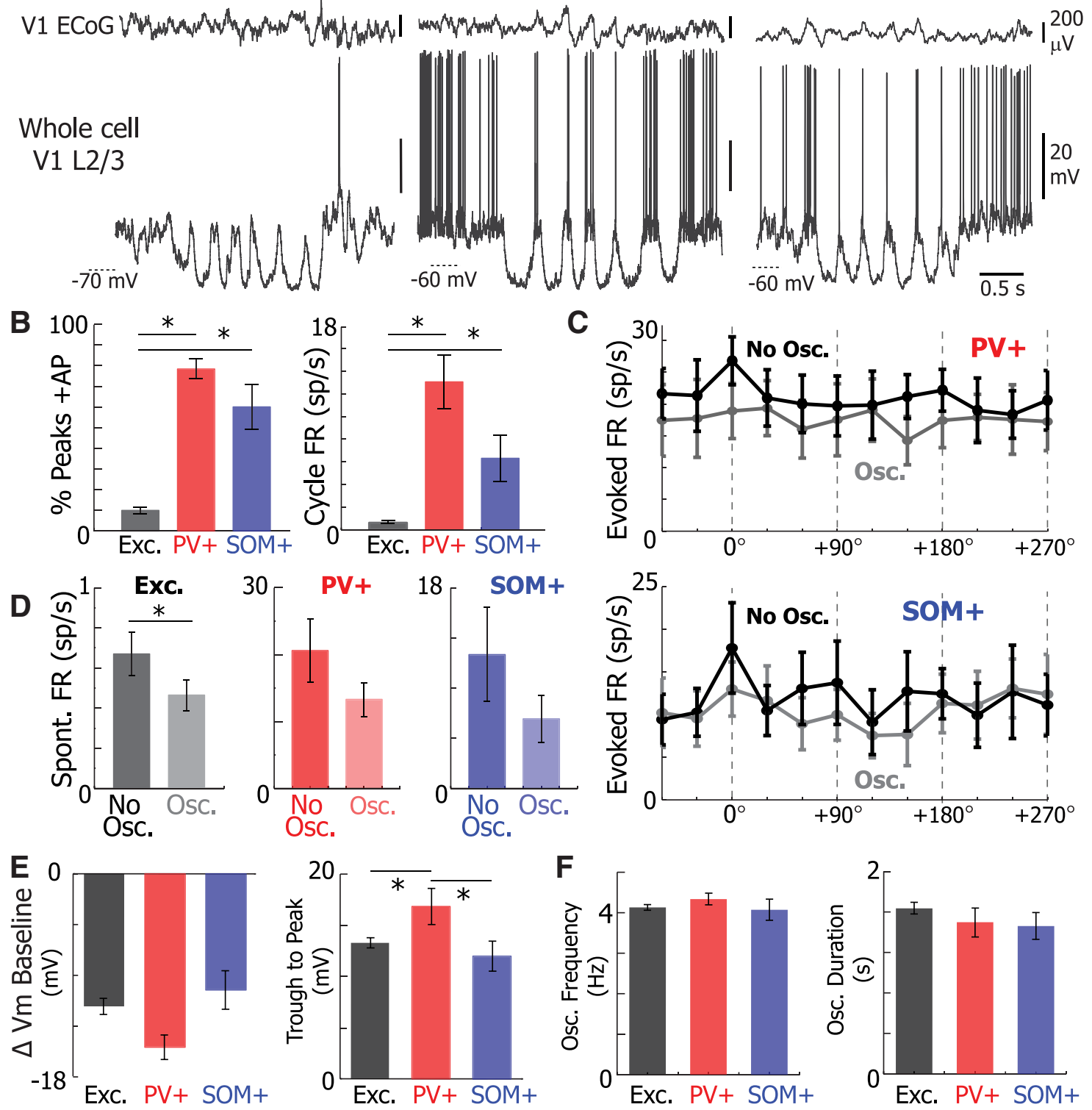

Figure 3. $\mathrm{PV}^{+}$and $\mathrm{SOM}{ }^{+}$neurons fire at the peaks of $3-5 \mathrm{~Hz} V_{\mathrm{m}}$ oscillatory cycles when excitatory neurons rarely fire. $A$, Simultaneous $\mathrm{V} 1 \mathrm{EC} 0 \mathrm{G}$ (top) and whole-cell recordings (bottom) from V1 L2/3 excitatory (left), $\mathrm{PV}^{+}$(center), and SOM ${ }^{+}$(right) neurons during $V_{\mathrm{m}} 3-5 \mathrm{~Hz}$ oscillations. $\boldsymbol{B}$, The percentage of peaks with at least one action potential (AP, left; one-way ANOVA $p=$ 2.71e-14) and the FR at the peaks of oscillations (one-way ANOVA $p=2.71 \mathrm{e}-14$ ) was significantly lower in excitatory neurons than in PV ${ }^{+}(\%$ AP, WRST, $p=0.0001 ;$ FR, WRST, $p=0.0001)$ and $\mathrm{SOM}^{+}(\%$ AP, WRST, $p=0.0008$; FR, WRST, $p=0.0006)$. C, Mean tuning curve of PV ${ }^{+}$and SOM ${ }^{+}$neurons. D, The baseline firing rates of excitatory (left), PV ${ }^{+}$(middle), and SOM ${ }^{+}$(right) neurons in the presence and absence of $3-5 \mathrm{~Hz} V_{m}$ oscillations. $E$, Plots of the mean change in $V_{m}$ baseline during $3-5 \mathrm{~Hz}$ oscillations (left) and mean oscillation trough to peak amplitude (right) for excitatory (black, $n=40$ ), $\mathrm{PV}^{+}$(red, $n=6$ ), and SOM ${ }^{+}$(blue, $n=7$ ) neurons. PV neurons experienced greater changes in trough to peak amplitude (one-way ANOVA, $p=0.01$ ) than excitatory neurons (Tukey-HSD, $p=0.01$ ) and SOM ${ }^{+}$neurons (Tukey-HSD, $p=0.04$ ) during $V_{\mathrm{m}} 3-5 \mathrm{~Hz}$ oscillations. Change in $V_{\mathrm{m}}$ baseline was similar between neuronal types (one-way ANOVA, $p=0.1$ ). $\boldsymbol{F}$, Plots of mean frequency (left) and duration (right) of $3-5 \mathrm{~Hz}$ oscillatory periods in excitatory (black, $n=40), \mathrm{PV}^{+}$(red, $n=6$ ), and SOM ${ }^{+}$(blue, $n=7$ ). Oscillation frequency and duration were unchanged between neuronal types (one-way ANOVA, $p=0.55$ and $p=0.43$, respectively). Error bars indicate SEM. ${ }^{*} p<0.05$.

for $3 \mathrm{~s}$, and animals had to make their decision in the final second of the visual stimulus presentation (the response period). Animals reliably learned how to perform the visual task in 5-10 training sessions and the auditory task in 1-3 sessions (Fig. 5C). All task behavioral parameters were identical in the visual and auditory tasks, except for the modality of the stimuli. During the auditory task, the monitor remained in the recording apparatus in the same location as the visual task and displayed an isoluminant gray screen, which was identical to the gray screen displayed during ITIs during the visual task.
When whole-cell recordings from V1 L2/3 were obtained in the trained animals, oscillations were recruited much more frequently during behavior when animals were exposed to drifting grating stimuli (Fig. $6 A-C$ ). The probability of a $3-5 \mathrm{~Hz} V_{\mathrm{m}}$ oscillation occurring during a trial was approximately fourfold higher during the visual task than during the auditory task (auditory $n=7$, visual $n=21, p=0.003$ WRST). During the visual task, oscillations were initiated on average $1.71 \pm 0.12 \mathrm{~s}(n=21$ neurons) after visual stimulus onset and were twice as likely to occur during visual stimulation than during ITIs (Fig. 6D, right). 
A

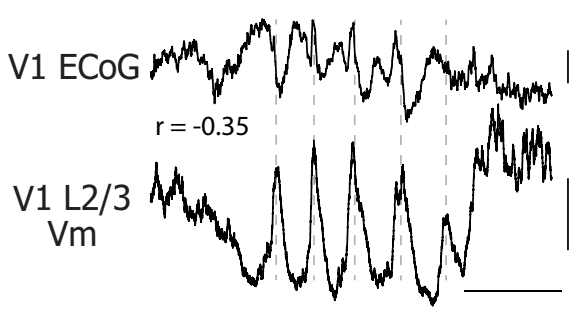

\section{B}

B 1 ECOG

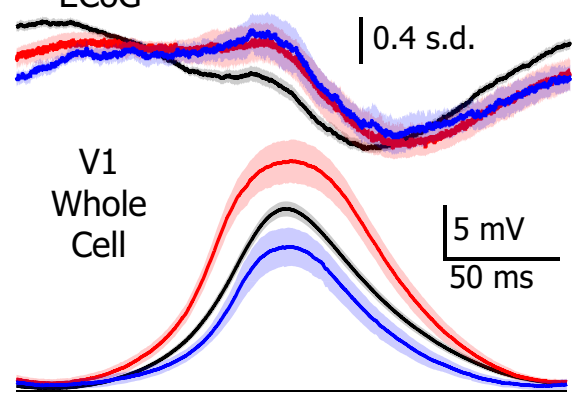

parvalbumin +

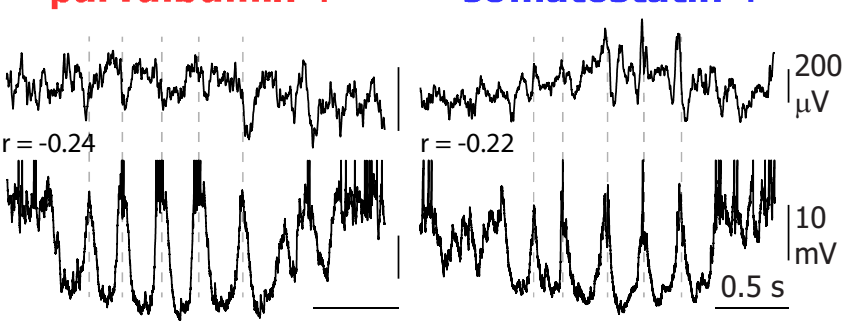

C

Exc.

$\mathrm{PV}+$

$\mathrm{SOM}+$

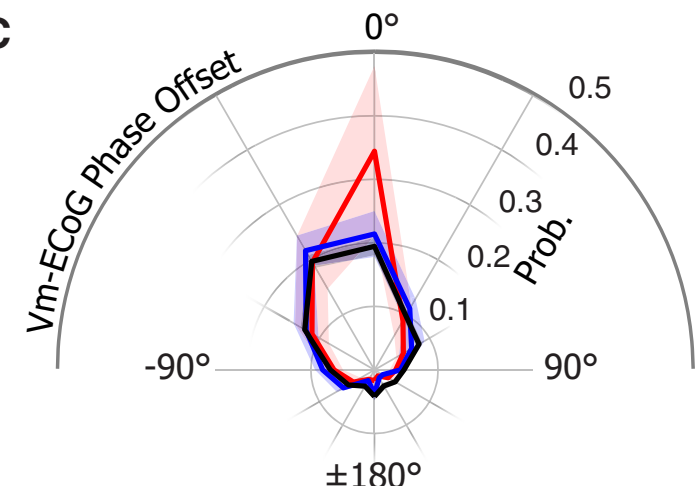

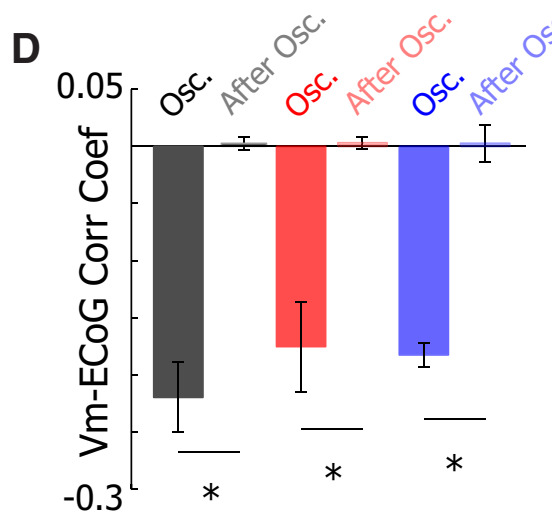
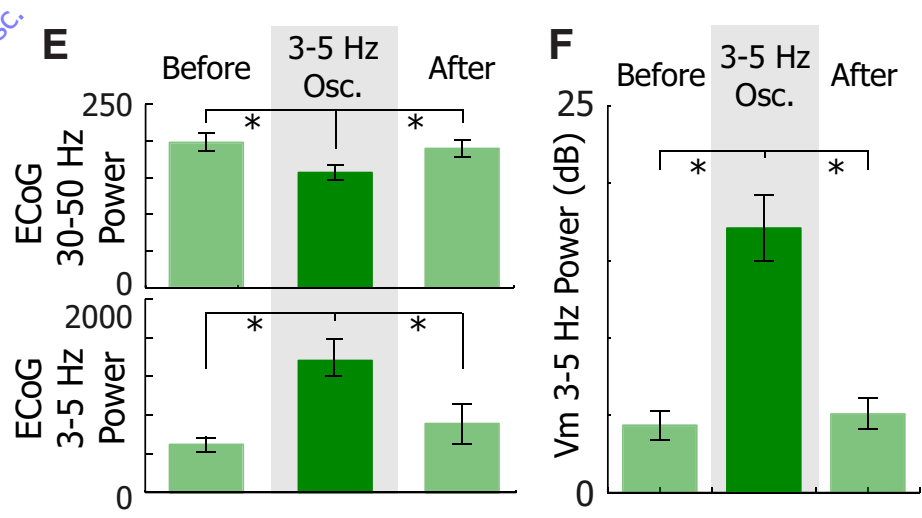

Figure 4. $\quad 3-5 \mathrm{~Hz} V_{\mathrm{m}}$ oscillations represent a transient synchronized network state. $A$, Example V1 ECoG (top) and V1 L2/3 $V_{\mathrm{m}}$ recordings from excitatory (left, black), PV ${ }^{+}$(middle, red), and $\mathrm{SOM}^{+}$(right, blue) neurons. Dotted gray lines were added to illustrate the phase relationship between the ECoG and $V_{\mathrm{m}} . \boldsymbol{B}$, Mean V1 $z$-score normalized ECoG (top) and mean $V_{\mathrm{m}}$ for Exc. (black, $n=$ $40), \mathrm{PV}^{+}(\mathrm{red}, n=6)$, and SOM ${ }^{+}$(blue, $n=7$ ) during an oscillation cycle. Traces were synchronized to the peak of the oscillation detected in the $V_{\mathrm{m}}$. EC $0 \mathrm{G}$ error bar indicates SD. $C$, Mean $V_{\mathrm{m}}$-EC $0 \mathrm{G}$ phase offset for excitatory (black), $\mathrm{PV}^{+}$(red), and SOM ${ }^{+}$(blue) neurons. $D, V_{\mathrm{m}}-\mathrm{ECOG}$ correlation coefficient is higher magnitude during oscillations than directly after an oscillation in all cell types (Exc., WSRT, $p=3.2 \mathrm{e}-8 ; \mathrm{PV}^{+}$, WSRT, $p=0.004 ; \mathrm{SOM}^{+}{ }^{+}$,WSRT, $p=5.8 \mathrm{e}-4$ ). $\boldsymbol{E}, \mathrm{V} 1 \mathrm{EC} 0 \mathrm{G} 30-50 \mathrm{~Hz}$ power (top) is higher (one-way ANOVA, $p<0.0001$ ) before (WSRT, $p<0.0001$ ) and after (WSRT, $p=0.0001$ ) an oscillation. The $3-5 \mathrm{~Hz}$ power is lower (one-way ANOVA, $p=0.0012$ ) before (WSRT, $p<0.0001$ ) and after (WSRT, $p<0.0001) 3-5 \mathrm{~Hz} V_{\mathrm{m}} 0$ oscillations. $\boldsymbol{F}$, The $3-5 \mathrm{~Hz}$ power is higher (one-way ANOVA, $p<0.0001$ ) before (WSRT, $p<0.0001$ ) and after (WSRT, $p<0.0001$ ) $3-5 \mathrm{~Hz} V_{\mathrm{m}}$ oscillations. Error bars and shading represent $S E M .{ }^{*} p<0.05$.

As found previously, 3-5 $\mathrm{Hz} V_{\mathrm{m}}$ oscillations coinciding with visual stimulation reduced the responsiveness of neurons to optimal visual stimuli (WSRT, $p=0.001$ ) but not orthogonal stimuli where response magnitude was already low (WSRT, $p=0.68$; Fig. $6 E$ ). No difference was detected in oscillation duration (WRST, $p=0.27)$ and oscillation onset latency from stimulus onset (WRST, $p=0.64$ ) between animals performing the visual and auditory tasks. The difference between oscillation probability during visual and auditory discrimination tasks was unlikely to be explained by differences in locomotion given that the probability of locomotion (WRST, $p=0.76$; Fig. $6 F$ ) was not different during visual and auditory discrimination tasks. Similarly, the animal's performance was similar for visual and auditory tasks (WRST, $p=0.37$; Fig. $6 F$ ); the mean $\mathrm{D}^{\prime}$ for both tasks exceeded 2 , and the median hit and false alarm (FA) rates were $96 \%$ and $33 \%$, respectively, during visual discrimination.

To test whether nonsalient visual cues could elicit 3-5 Hz $V_{\mathrm{m}}$ oscillations during behavior, a subset of animals $(n=5)$ per- formed trials of the auditory task where nonsalient visual cues (the visual cues did not predict reward) were displayed simultaneously with salient auditory cues (Fig. 6G). Displaying visual cues rescued oscillation recruitment during the auditory task as there was no difference in the probability of evoking an oscillation during the auditory task + visual cues $(\mathrm{A}+\mathrm{V}$ task) and the traditional visual discrimination task (Fig. 6G,H). However, oscillations probability was not significantly different between when the stimulus was on or off in the A+V task (WSRT, $p=$ 0.17; Fig. $6 H$ ). This finding suggests that visual stimulation itself, not its behavioral salience, plays a critical role in provoking 3-5 $\mathrm{Hz}$ oscillations.

Behavioral context does not change the overall probability of oscillations but does affect their timing

Visual cues reliably recruited $3-5 \mathrm{~Hz} V_{\mathrm{m}}$ oscillations in untrained animals not performing a behavior (Fig. 7). The number of 3-5 $\mathrm{Hz} V_{\mathrm{m}}$ oscillations elicited per minute of recording during pas- 

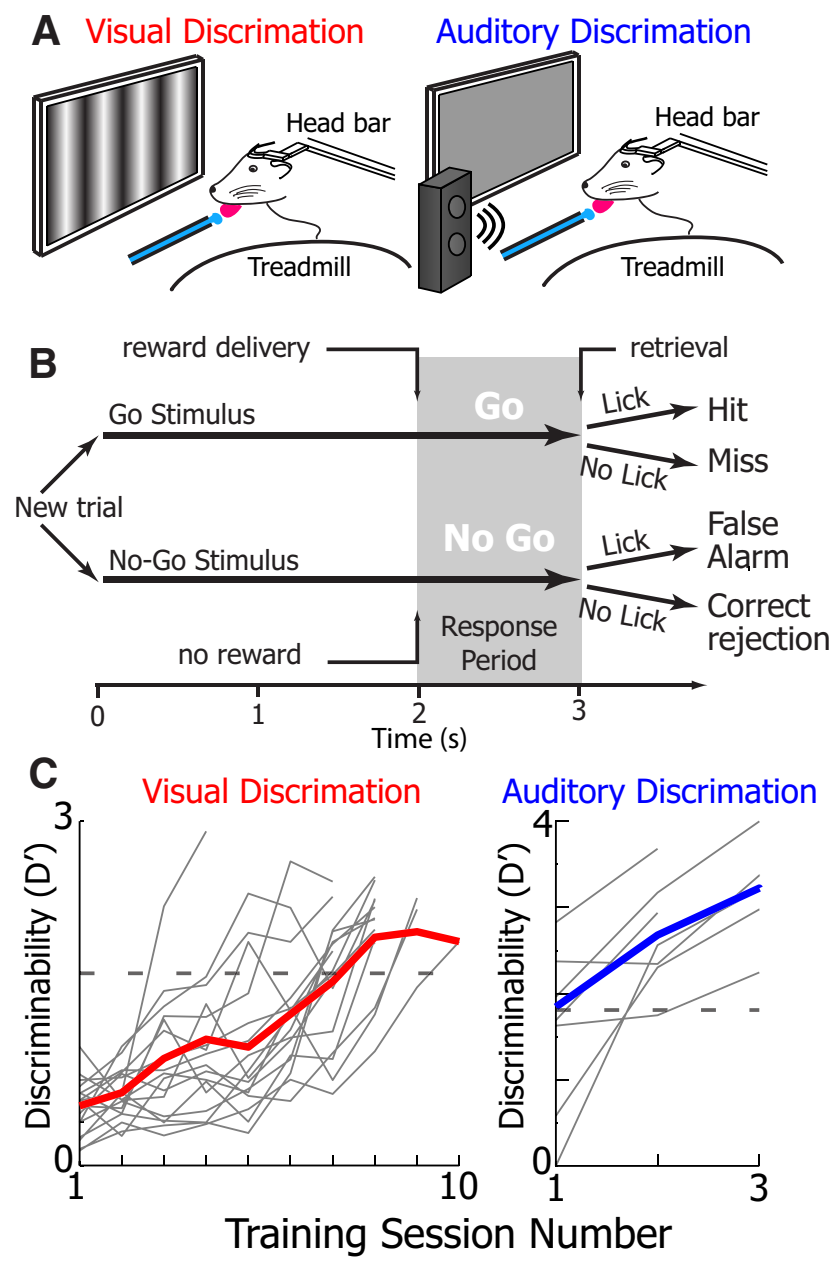

Figure 5. Go/No-Go discrimination task schematics and learning curves. A, Schematic of the animal performing the visual (left) and auditory (right) discrimination tasks. During both tasks, animals were head-fixed atop a friction-less spherical treadmill, a monitor was placed in the monocular visual field, and a water dispenser with reward retrieval vacuum and lick monitoring was used to deliver rewards. Illumination levels were identical during auditory and visual discrimination tasks (for more details, see Materials and Methods). B, Task schematic. Visual and auditory stimuli were presented for $3 \mathrm{~s}$. In Go trials, $45^{\circ}$ gratings or a $5 \mathrm{kHz}$ tone were played and a water reward was issued 2 s after stimulus onset. During No-Go trials, $135^{\circ}$ gratings or a $10 \mathrm{kHz}$ tone were played and no reward was issued. Animal response (licking) was recorded during the response period to assess correct behavior (for more details, see Materials and Methods). C, The mean discriminability, a measure of animal performance, of animals during learning of the visual (left, red, $n=17$ animals) and auditory (right, blue) discrimination tasks ( $n=7$ mice). Bold colored line indicates the mean performance of all animals on a given session date. Light gray lines indicate the mean performance of a single animal on a given session date. Animals were recorded once their mean discriminability surpassed $D^{\prime}=1.7$ (Monte Carlo simulation, $p=0.01$ random behavior) indicated by the gray dotted line.

sive viewing of drifting gratings was significantly higher than during periods when no visual cues were shown for at least 5 min (WSRT, $p=1 \mathrm{e}-7$ ) in untrained animals naive to the visual stimuli (Fig. 7A). Similarly, the number of $3-5 \mathrm{~Hz} V_{\mathrm{m}}$ oscillations per minute was significantly different when animals performed the visual task compared with the auditory discrimination task (WRST, $p=0.008$; Fig. $7 B$ ). Finally, the probability of evoking an oscillation during a trial (stimulus and ITI) of the visual task and passive viewing was not different (WRST, $p=0.26$; Fig. $7 C$ ). Visual cues during passive viewing and visual discrimination were identical except in their duration ( $1.5 \mathrm{~s}$ during passive viewing, $3 \mathrm{~s}$ during visual discrimination). Therefore, $3-5 \mathrm{~Hz} V_{\mathrm{m}}$ oscillations were elicited by visual cues to a similar degree in trained animals performing a visual discrimination task and untrained animals passively viewing drifting gratings.

However, the timing of $3-5 \mathrm{~Hz} V_{\mathrm{m}}$ oscillations in relation to visual stimuli was markedly different in these two behavioral contexts. During passive viewing of either 1.5 or $3 \mathrm{~s}$ visual stimuli, the mean probability of oscillations occurring at the offset of the stimulus was 2.2 -fold ( $n=53$, WSRT, $p=7.2 \mathrm{e}-9)$ and 2.5 -fold $(n=9$, WSRT, $p=0.004)$ greater than the probability of occurrence during visual stimuli, respectively (Fig. $7 D, E)$. As a result, 3-5 Hz $V_{\mathrm{m}}$ oscillation probability was higher during the visual stimulus (WRST, $p=0.001$; Fig. $7 E$, left) and lower after the visual stimulus (WRST, $p=0.007$; Fig. $7 E$, right) in active behavior compared with passive viewing, although when $3-5 \mathrm{~Hz} V_{\mathrm{m}}$ oscillations coincided with visual cues, the responsiveness of excitatory neurons to cues that evoked a strong response was reduced during passive viewing (Fig. $2 A, B$ ). The probability that a neuron was recruited in a $3-5 \mathrm{~Hz} V_{\mathrm{m}}$ oscillation did not depend its orientation tuning in passive viewing (one-way ANOVA, $p=$ 0.76 ) and visual discrimination (WSRT, $p=0.34$; Fig. $7 F, G$ ).

The $3-5 \mathrm{~Hz} V_{\mathrm{m}}$ oscillation prevalence and timing were also investigated in the context of animals' responses during visually guided behavior (Fig. 8). The $3-5 \mathrm{~Hz} V_{\mathrm{m}}$ oscillation prevalence was significantly higher during trials when animals correctly withheld licking (correct rejection [CR]; for schematic of behavior, see Fig. $4 B$ ) than during trials when animals initiated a licking response either correctly (hit) or incorrectly (FA; $n=21$, WSRT Bonferroni-corrected $p=0.046, p=0.04$, respectively; Fig. $8 A$ ). Importantly, the visual stimulus was identical in FA and CR trials. Yet, there was no difference in $3-5 \mathrm{~Hz} V_{\mathrm{m}}$ oscillation prevalence between incorrect and correct behavioral response (hit vs FA, WSRT Bonferroni-corrected, $p=0.9$; CR vs miss, WSRT Bonferroni-corrected, $p=0.86$; Fig. $8 A$ ). Additionally, $3-5 \mathrm{~Hz}$ $V_{\mathrm{m}}$ oscillation duration was slightly longer during CR trials than during hit trials (WSRT Bonferroni-corrected, $p=0.035$ ), but not FA trials (WSRT Bonferroni-corrected, $p=0.3$; Fig. $8 B$ ). The high prevalence of $3-5 \mathrm{~Hz} V_{\mathrm{m}}$ oscillations during $\mathrm{CR}$ trials disproves the hypothesis that the motor action associated with licking response triggers oscillations because licking is typically absent during CR trials. Moreover, animals did not receive rewards during $\mathrm{CR}$ trials, indicating that reward expectation was not the primary factor in evoking $3-5 \mathrm{~Hz}$ oscillations in V1.

Additionally, 3-5 Hz oscillation onset typically occurred after licking onset for correct (hit, WSRT, $p=0.01$ ) and incorrect (FA, WSRT, $p=0.001$ ) Go responses (Fig. $8 C$ ). On a trial by trial basis, oscillation onset followed licking in $86 \pm 0.6 \%(n=21)$ of hit and FA trials on average by $0.47 \pm 0.05$ s. For trials where licking preceded the response period in correct No-Go trials (CR), licking offset occurred before $3-5 \mathrm{~Hz}$ oscillation onset (WSRT, $p=$ 0.031 ). There was no difference in oscillation onset time across behavioral responses (repeated-measures one-way ANOVA, $p=$ 0.35). Therefore, $3-5 \mathrm{~Hz}$ oscillations tended to follow the animal's behavioral response to the Go/No-Go visual cue.

The $3-5 \mathrm{~Hz} V_{\mathrm{m}}$ oscillations occur during high and low arousal states during visual discrimination

Locomotion and dilated pupils, both indicators of a high arousal state and increased noradrenergic tone, have been linked to suppression of 1-10 Hz $V_{\mathrm{m}}$ fluctuations in V1 neurons of awake mice (Bennett et al., 2013; Polack et al., 2013; Reimer et al., 2014; McGinley et al., 2015; Vinck et al., 2015). To investigate how arousal contributes to $3-5 \mathrm{~Hz}$ oscillation generation, we analyzed how locomotion and pupil size correlated with oscillation probability during the visual discrimination task (Fig. 9A). Locomo- 


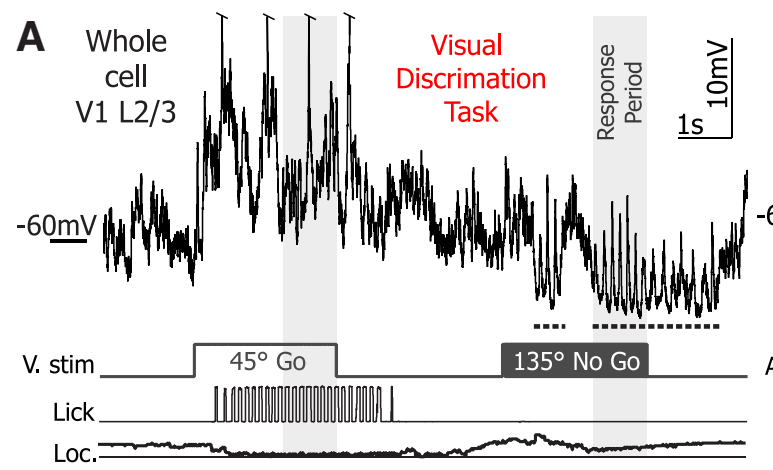

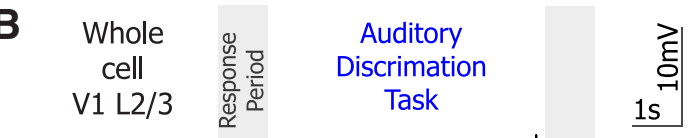
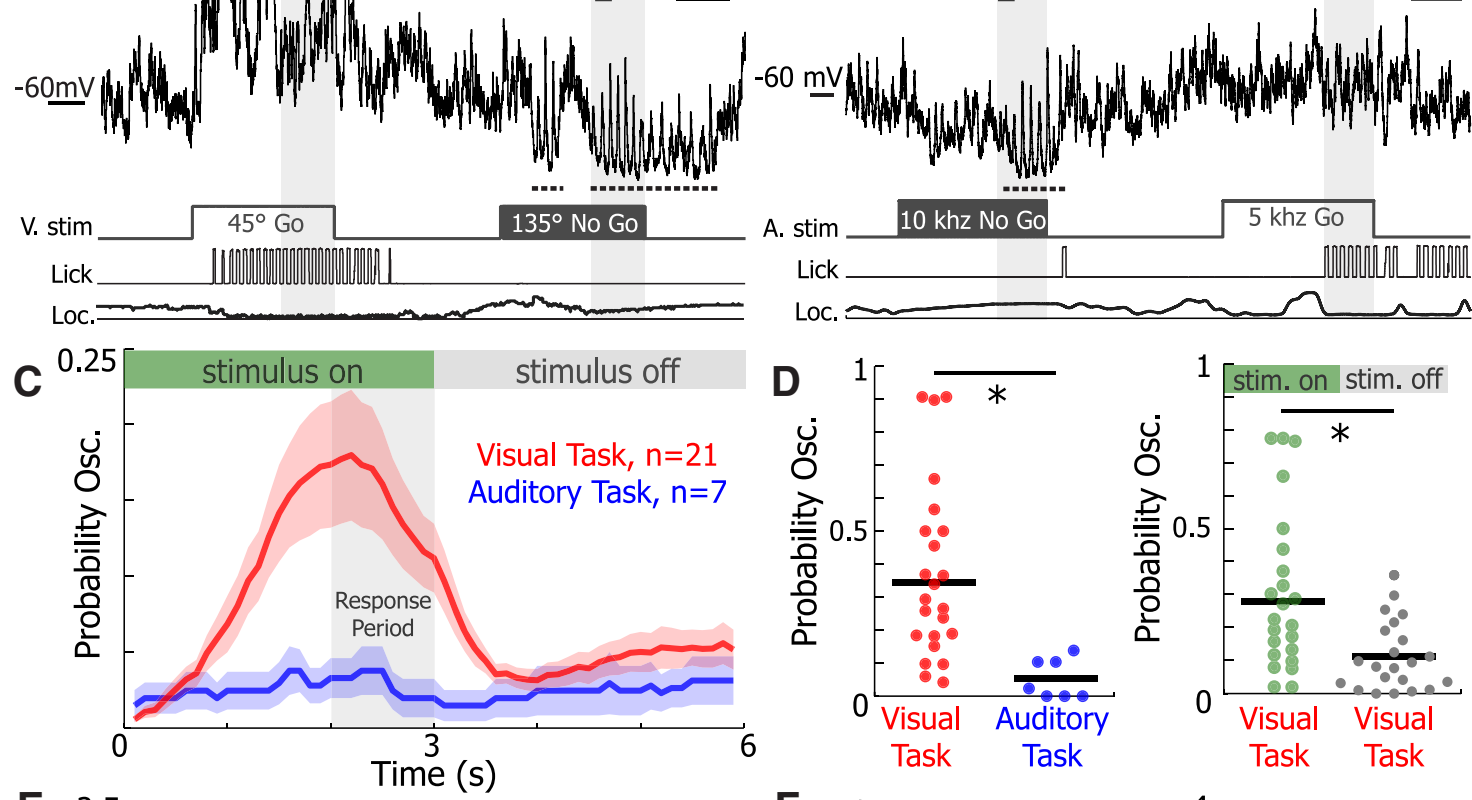

\section{E}
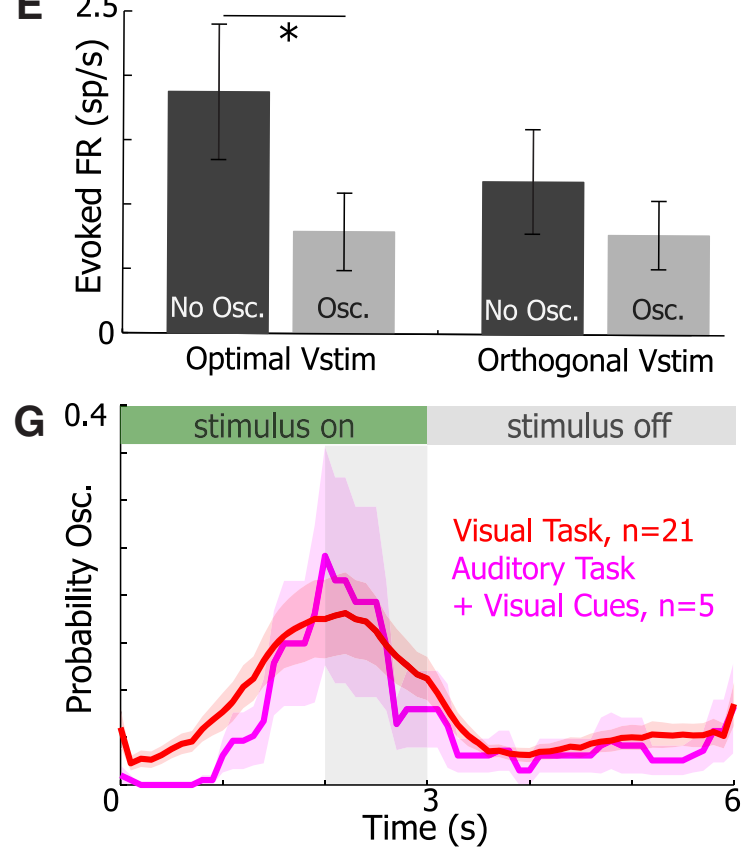
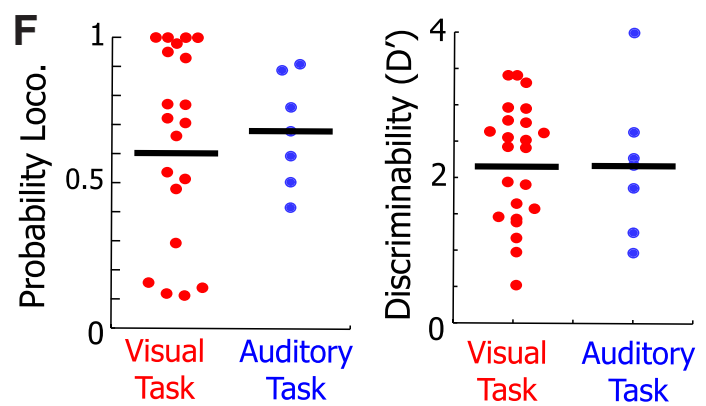

H

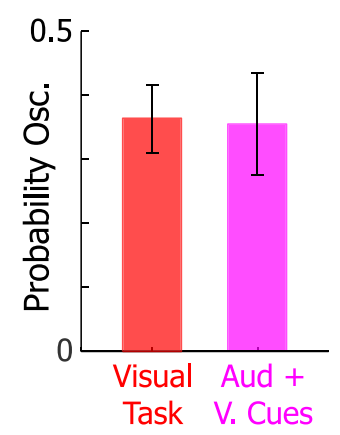

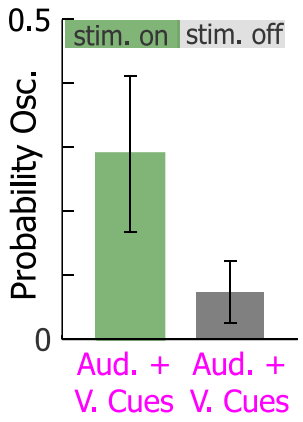

Figure 6. $3-5 \mathrm{~Hz} V_{\mathrm{m}}$ oscillations are recruited during visual stimulation in behaving animals. Example subthreshold activity from single neurons as animals perform the ( $A$ ) visual discrimination and (B) auditory discrimination tasks. Stimuli timing, licking, and locomotion were recorded simultaneously. Dotted underline indicates $3-5 \mathrm{~Hz} V_{\mathrm{m}}$ oscillation occurrences. $\boldsymbol{C}$, The mean probability of 3-5 Hz $V_{m}$ oscillations occurring during a trial of the visual (red, $n=21$ neurons) and auditory (blue, $n=7$ neurons) Go/No-Go tasks. Periods where stimuli were on and offare marked at the top. The response period, when the animal must report its decision, is denoted in the gray region. $D$, The probability of an oscillation occurring during a trial in the visual task was significantly greater than in the auditory task (left, WRST, $p=$ 0.001). The probability of an oscillation occurring during the visual task was significantly higher than when the stimulus was off(right, WSRT, $p=0.0037$ ). $\boldsymbol{E}$, The mean firing rate evoked by optimal visual stimuli (left, WSRT, $p=0.001$ ) and orthogonal visual stimuli (right, WSRT, $p=0.68$ ) when 3-5 Hz oscillations were present (osc.) or absent (no osc.) in neurons recorded from animals during visual discrimination ( $n=$ 21 neurons). $\boldsymbol{F}$, There was no difference in the probability of locomotion during a trial (WRST, $p=0.92$ ) and the mean discriminability $\left(\mathrm{D}^{\prime}\right)$ during a behavioral session (WRST, $p=0.72$ ) during the visual (red) and auditory task (blue). G, The mean probability of $3-5 \mathrm{~Hz}$ oscillations occurring during a trial of the visual (red, $n=21$ neurons) and auditory task + visual cues (Aud. + V. Cues, pink, $n=5$ neurons) task. Visual cues in the auditory task + visual cues trials were not salient and were displayed simultaneously with auditory cues identical in the auditory task. $\boldsymbol{H}$, The probability of an oscillation occurring during a trial in the auditory task + visual cues was not different from the visual task (WRST, $p=0.82$ ). The probability of an oscillation occurring while stimuli were on (green) versus off (gray) was statistically not different during the auditor task + visual cues (WSRT, $p=0.17$ ). Error bars and shaded regions represent SEM. ${ }^{*} p<0.05$.

tion was measured in all animals who completed the visual discrimination task $(n=21)$. Four animals who completed visual discrimination also had pupil size measured concurrently to whole-cell recording. Presence of locomotion (sustained tread- mill motion $>2 \mathrm{~cm} / \mathrm{s}$ for at least $1 \mathrm{~s}$; see Materials and Methods) during trials of the visual discrimination task did not change oscillation probability during a trial of task (WSRT, $p=0.76$; Fig. $9 B, D)$. Moreover, the oscillation incidence was not different dur- 
A

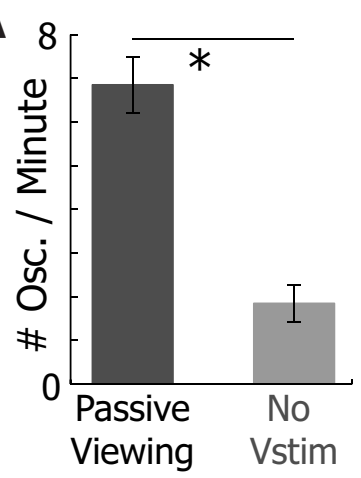

B

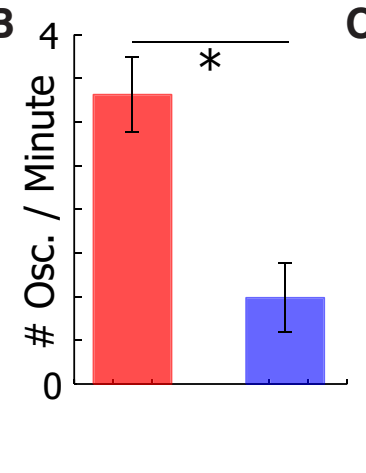

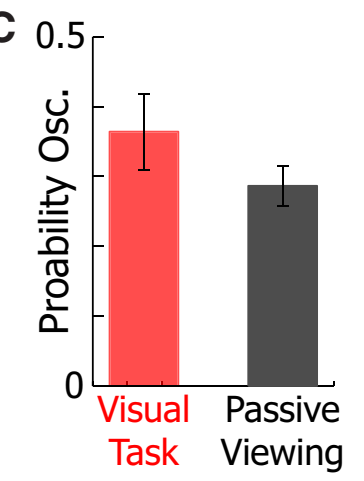

D
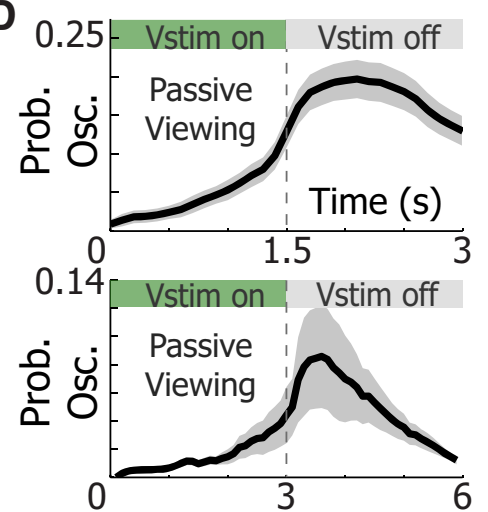

$\mathbf{F}$

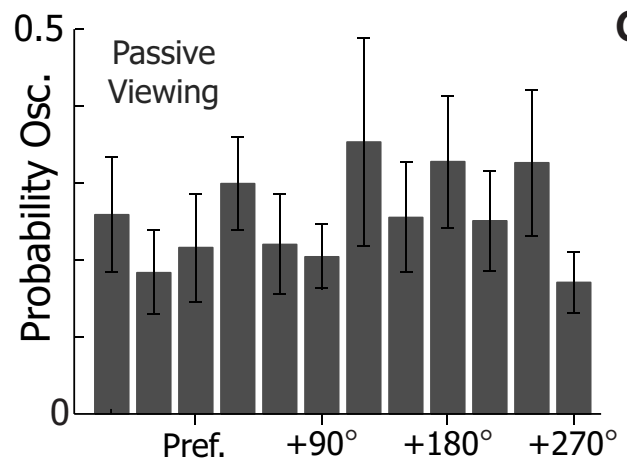

$E$

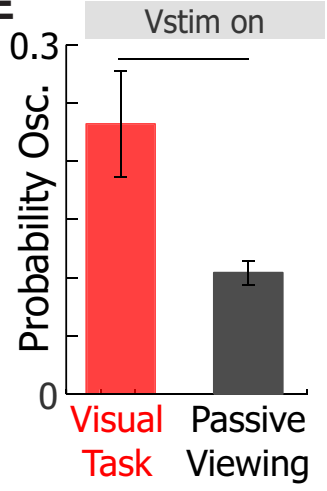

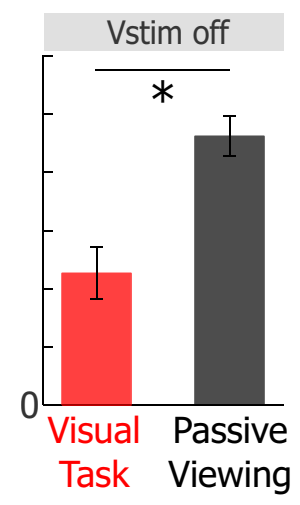

G 0.5

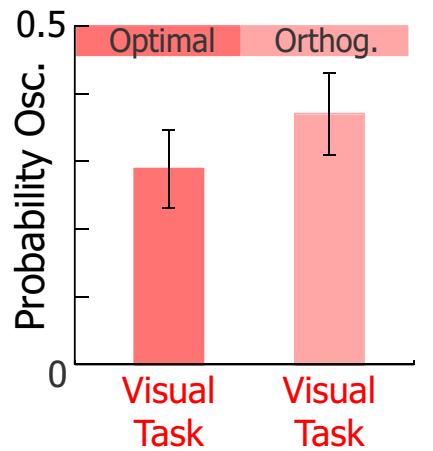

Figure 7. Visual stimulation recruits $3-5 \mathrm{~Hz} V_{\mathrm{m}}$ oscillations during passive viewing, but oscillations tend to occur after the visual stimulus during passive viewing. $A$, The number of oscillations per minute was higher during passive viewing (black) of $1.5 \mathrm{~s}$ drifting gratings than $5-10$ min periods where no visual stimuli were shown (No vstim, gray; WSRT, $p=1.7 \mathrm{e}-5$ ). $\boldsymbol{B}$, The number of oscillations per minute was higher during the visual task (red) than the auditory (blue) discrimination task (WRST, $p=0.008$ ). C, The probability of $3-5 \mathrm{~Hz} V_{\mathrm{m}}$ oscillations during a trial was not different during the visual task and passive viewing (WRST, $p=$ 0.26). $\boldsymbol{D}$, The probability of evoking an oscillation during passive viewing when the visual stimulus is $1.5 \mathrm{~s}$ (top, $n=40$ ) or $3 \mathrm{~s}$ (bottom, $n=9$ ). $\boldsymbol{E}$, Comparison of the mean probability of $3-5 \mathrm{~Hz} V_{\mathrm{m}}$ oscillations occurring in neurons recorded from animals during the visual task (red, $n=21$ ) and passive viewing (gray, $n=53$ ) while a visual stimulus is on (left, WRST, $p=0.001$ ) and off (right, WRST, $p=0.007) . F$, The probability of a $3-5 \mathrm{~Hz} V_{\mathrm{m}}$ oscillation occurring during passive viewing of visual cues in relation to excitatory neuron ( $n=40$, one-way ANOVA, $p=0.76$ ) tuning. Pref., Preferred visual stimulus. G, The probability of a $3-5 \mathrm{~Hz} V_{\mathrm{m}}$ oscillation occurring during visual discrimination of the optimal or orthogonal visual stimulus ( $n=21$ neurons, WSRT, $p=0.34$ ). Error bars indicate SEM. ${ }^{*} p<0.05$.

ing the locomotion and stationary periods (Fig. 9F). Similarly, there was no change in oscillation probability between trials when the mean pupil size was dilated (pupil size $>50 \%$ ) or constricted (pupil size $<50 \%$; WSRT, $p=0.63$; Fig. $9 C, E$ ). In addition, the oscillation incidence was similar across a wide range of pupil sizes (one-way ANOVA, $p=0.96$; Fig. $9 G$ ), showing that $3-5 \mathrm{~Hz} V_{\mathrm{m}}$ oscillations occur during both low and high arousal states.

The $3-5 \mathrm{~Hz} V_{\mathrm{m}}$ oscillations were correlated with small reductions in speed and pupil size during oscillations (Fig. 10B). Locomotion speed was slightly lower (one-way repeated-measures ANOVA,

$p<0.0001)$ during the oscillations compared with before (WSRT, Bonferronicorrected $p=0.0001$ ) and after (WSRT, Bonferroni-corrected $p=0.0176$ ) the oscillation (Fig. 10B). Locomotion speed was also slightly lower after $3-5 \mathrm{~Hz} V_{\mathrm{m}}$ oscillations than before oscillations occurred ( $p=0.0011$; Fig. 10B). Although animals on average slowed during the oscillation, they did not terminate locomotion. Pupil size was lower during the oscillation compared with before the oscillation (WSRT, Bonferroni-corrected $p=0.028$ ) but was no different compared with after the oscillation (WSRT, Bonferroni-corrected $p=0.34$; Fig. $10 C)$. Moreover, there was no difference in pupil size before and after the oscillation (WSRT, Bonferroni-corrected $p=0.79$; Fig. $10 C$, right).

In other studies of $V_{\mathrm{m}}$ in awake mice, locomotion onset and offset have been explicitly linked to the reduction and generation of $1-10 \mathrm{~Hz}$ fluctuations in the $V_{\mathrm{m}}$ of cortical neurons, respectively (Poulet and Petersen, 2008; Reimer et al., 2014; Vinck et al., 2015). To investigate whether locomotion onset or offset affects $3-5 \mathrm{~Hz} V_{\mathrm{m}}$ oscillation probability, we calculated the probability of an oscillation occurring in $3 \mathrm{~s}$ before or after locomotion onset and offset (Fig. 9D,E). We found that the probability of evoking a $3-5 \mathrm{~Hz} V_{\mathrm{m}}$ oscillation just after locomotion onset was slightly lower than before locomotion onset (WSRT, $p=0.012$; Fig. 9D). However, the probability of an oscillation occurring following locomotion offset was no different from the probability of an oscillation occurring just before locomotion offset (WSRT, $p=0.36$; Fig. 9E). Therefore, locomotion onset may have a slightly suppressive effect on 3-5 $\mathrm{Hz} V_{\mathrm{m}}$ generation; however, locomotion offset has no discernable effect on evoking $3-5 \mathrm{~Hz} V_{\mathrm{m}}$ oscillations.

Pupil constriction has recently been shown to closely correspond with increased 2-10 Hz $V_{\mathrm{m}}$ amplitude (Reimer et al., 2014). We identified when the pupil was dilating or constricting (Fig. 10A) in our recordings and then analyzed $3-5 \mathrm{~Hz} V_{\mathrm{m}}$ oscillation probability at pupil dilation and constriction onset (Fig. 10F, G). The probability of evoking a $3-5 \mathrm{~Hz} V_{\mathrm{m}}$ oscillation was no greater after pupil dilation (WSRT, $p=0.91$ ) or pupil constriction (WSRT, $p=0.25$ ) onset than immediately preceding the dilation or constriction. These data do not contradict prior findings. The $1-10 \mathrm{~Hz} V_{\mathrm{m}}$ power can be tracked by following pupil size, especially because pupil size tends to decrease during 3-5 $\mathrm{Hz} V_{\mathrm{m}}$ oscillations (Fig. 10C). Instead, our data suggest that $3-5 \mathrm{~Hz}$ $V_{\mathrm{m}}$ oscillations are distinct events that exist within the $2-10 \mathrm{~Hz}$ power band but do not represent all periods when $2-10 \mathrm{~Hz}$ power is increased in awake animals. This hypothesis is corroborated by the finding that the $V_{\mathrm{m}}$ power spectra differ significantly during $3-5 \mathrm{~Hz}$ 
$V_{\mathrm{m}}$ oscillations and at constriction onset (Fig. 10H). Finally, the pupil size did not increase during visual stimulus presentations, and pupil $x$ and $y$ movements were limited during visual stimulation (Fig. $10 I, J)$.

\section{Discussion}

We describe stereotyped 3-5 Hz $V_{\mathrm{m}}$ oscillations in V1 L2/3 neurons that significantly reduce the responsiveness of excitatory neurons. During these oscillations, individual neuron's $V_{\mathrm{m}}$ fluctuated in phase with the local network, creating a transient synchronous brain state marked by rhythmic firing of inhibitory $\mathrm{PV}^{+}$and $\mathrm{SOM}^{+}$neurons. Despite this disruption in coding of visual information, $3-5 \mathrm{~Hz} V_{\mathrm{m}}$ oscillations were evoked by visual stimulation and occurred frequently in animals passively viewing drifting gratings or performing an active discrimination task. The probability of an oscillation occurring during a stimulus was unchanged by locomotion or pupil size, suggesting that these transient oscillations occur in both high and low arousal states.

Similar low-frequency $V_{\mathrm{m}}$ oscillations have been observed in passing in visual (Bennett et al., 2013; Polack et al., 2013), barrel (Crochet and Petersen, 2006; Poulet and Petersen, 2008), auditory (Schneider et al., 2014; Zhou et al., 2014; McGinley et al., 2015), and motor (Zagha et al., 2015) cortex neurons in awake mice. While the $3-5 \mathrm{~Hz} V_{\mathrm{m}}$ oscillations described in this study seem to be present in example traces in these prior studies, they were not isolated as specific events and clumped together with other factors that contributed to increased $1-10 \mathrm{~Hz} V_{\mathrm{m}}$ power during long periods where animals were inactive or lowly aroused. We show that these $3-5 \mathrm{~Hz} V_{\mathrm{m}}$ oscillations are distinct lowfrequency events that occur when animals are active or inactive, challenging the hypothesis that significant low-frequency fluctuations in $V_{\mathrm{m}}$ are exclusive to idle animals. Moreover, $3-5 \mathrm{~Hz} V_{\mathrm{m}}$ oscillations are not canonical UP and DOWN states as these $V_{\mathrm{m}}$ oscillations are faster with significantly shorter depolarized time than the UP and DOWN oscillations that are typically square shaped (Petersen et al., 2003; Haider and McCormick, 2009). In the future, it will be important to examine when $3-5 \mathrm{~Hz} V_{\mathrm{m}}$ oscillations occur in other sensory areas and whether they have similar effects on sensory processing.

We hypothesize that $3-5 \mathrm{~Hz} V_{\mathrm{m}}$ oscillations are local phenomena. Precedent exists for transient low-frequency microsleep LFP events that reduce the firing of the network occurring in an isolated cortical network (Vyazovskiy et al., 2011). While the $V_{\mathrm{m}}$ of neurons becomes significantly more correlated to the ECoG (which was collected $\sim 0.5 \mathrm{~mm}$ away from the whole-cell recording), the correlation coefficient magnitude tends to be low $(\sim-0.2$; Fig. $3 C$ ) and variable between oscillatory epochs (Fig. 2A). In similar $V_{\mathrm{m}}$ oscillations $(1-10 \mathrm{~Hz})$ observed in anesthetized cat preparations, weak correlations between $V_{\mathrm{m}}$ and EEG have been described as local to the cortical area (Lampl et al., 1999). $V_{\mathrm{m}}$ oscillations that extend across cortical areas, and even hemispheres, have been found in anesthetized animals but tend to be at very low frequencies $(<1 \mathrm{~Hz})$ and present with strong correla- tions between the $V_{\mathrm{m}}$ and EEG (Amzica and Steriade et al., 1995; Contreras and Steriade, 1995). As a result, 3-5 Hz $V_{\mathrm{m}}$ oscillations may be local and not global cortical events.

The $3-5 \mathrm{~Hz} V_{\mathrm{m}}$ oscillations may decrease the responsiveness of excitatory neurons to sensory cues in at least one of the following ways: (1) the hyperpolarized $V_{\mathrm{m}}$ baseline during oscillatory sequences likely reduces the response magnitude to incoming signals (Carandini and Ferster, 1997; Nowak et al., 2005; Cardin et al., 2008); (2) during the depolarizing phases of the oscillations where excitatory neurons' $V_{\mathrm{m}}$ is closest to reaching spike threshold, excitatory neurons received strong perisomatic and dendritic inhibition from GABAergic $\mathrm{PV}^{+}$and $\mathrm{SOM}^{+}$neurons, respectively (Taniguchi, 2014) (Fig. 2); and (3) sensory signals out of phase with $3-5 \mathrm{~Hz} V_{\mathrm{m}}$ oscillations could filter inbound sensory signals of a different time structure (i.e., incoming EPSPs at the trough of the oscillation would be less likely to drive the $V_{\mathrm{m}}$ to threshold) (Engel et al., 2001; Lakatos et al., 2008; Schroeder and Lakatos, 2009). The exact contribution of each of these three components to the suppression of visual responsiveness is still unclear. However, considering the combination of these three mechanisms, 3-5 $\mathrm{Hz} V_{\mathrm{m}}$ oscillations represent a potent combination of inhibitory strategies to reduce the responsiveness of excitatory sensory neurons.

One role $3-5 \mathrm{~Hz} V_{\mathrm{m}}$ oscillations could play is to reduce processing of irrelevant visual information. In our behavioral experiments, we found that $3-5 \mathrm{~Hz} V_{\mathrm{m}}$ oscillations were most prevalent after animals had expressed their decision during visual discrimination, a point in the task when additional visual inputs were irrelevant to completing the task. Such a mechanism could be particularly useful during behaviors, such as attention and working memory. When nonhuman primates ignore visual cues during attention tasks, neurons in V4 increase their correlated firing at frequencies between 3 and $5 \mathrm{~Hz}$, spiking synchronizes within low-frequency bands $(<10 \mathrm{~Hz})$ of the LFP (Fries et al., 2001; Mitchell et al., 2009), and LFP power between 3 and $5 \mathrm{~Hz}$ 
A Visual Stimulus

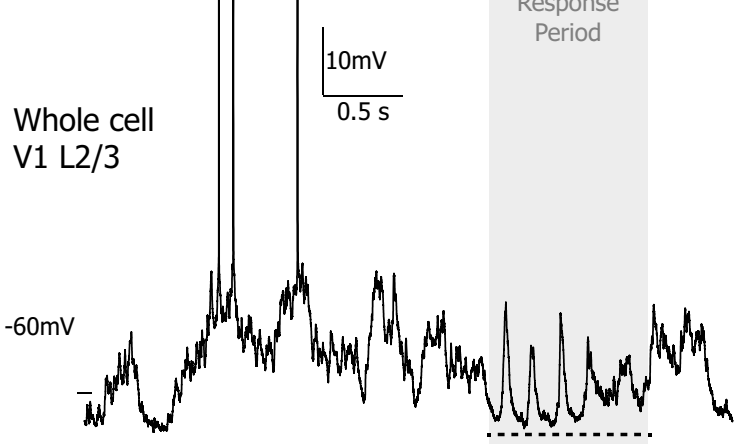

Licking
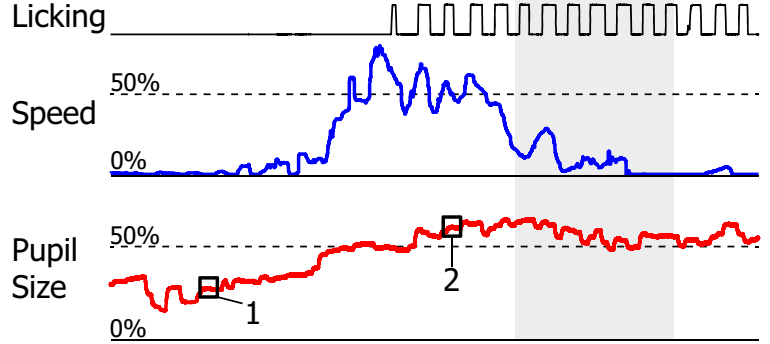

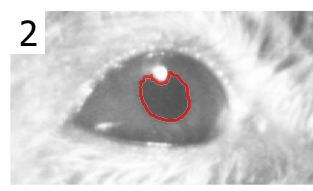

B

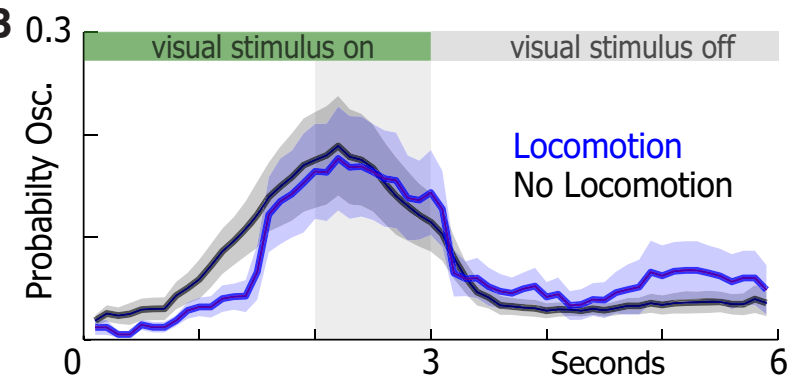

C 0.4

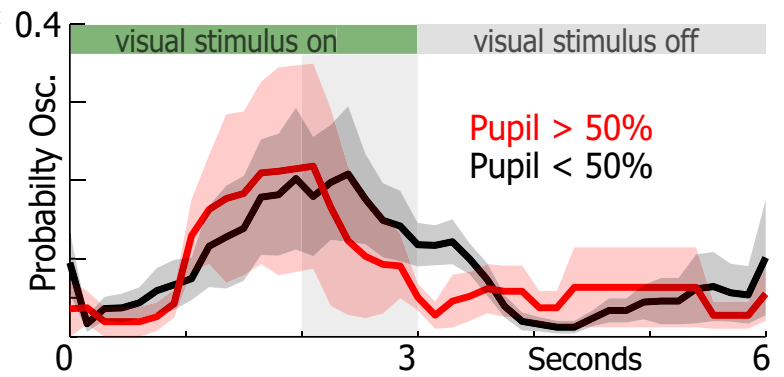

D 0.45
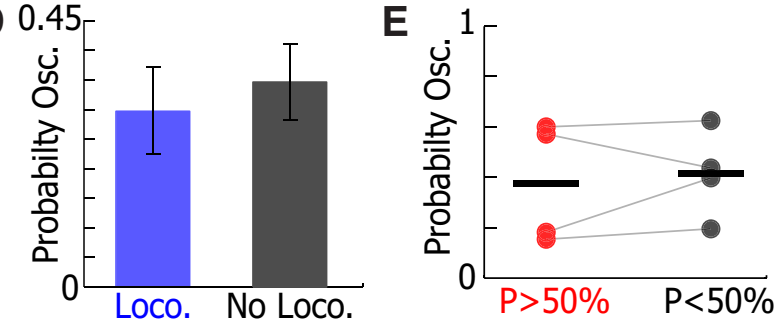
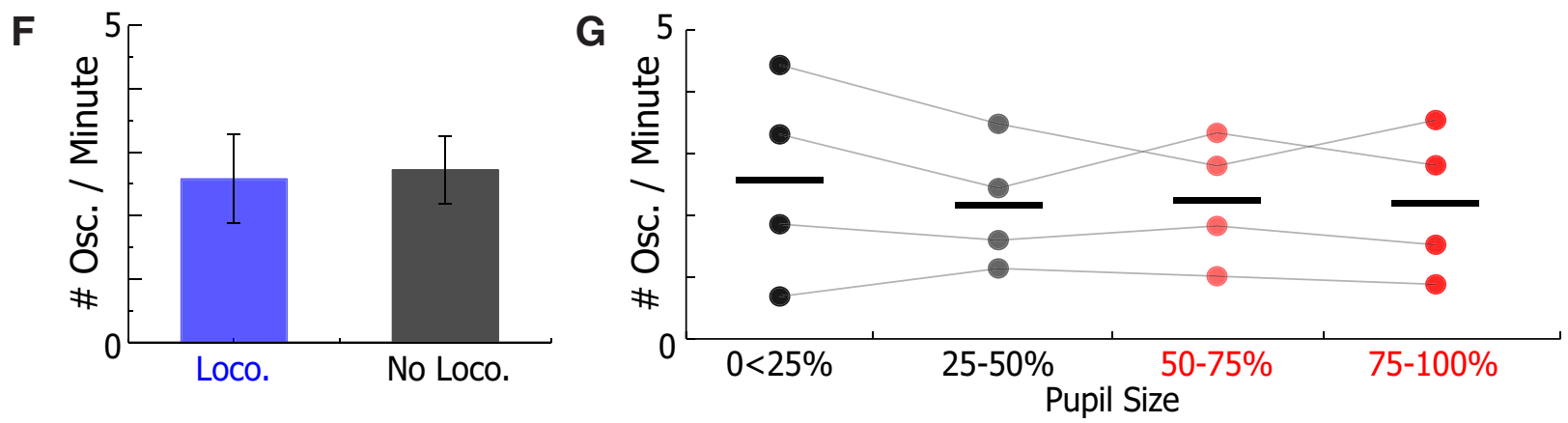

Figure 9. Oscillations occurred in high and low arousal states. $A$, Example of a whole-cell recording from a V1 L2/3 neuron during the visual discrimination task where speed (blue) and pupil size (red) were simultaneously recorded. The $3-5 \mathrm{~Hz} V_{m}$ oscillation is underlined by the dotted line. $\boldsymbol{B}$, The mean probability of $3-5 \mathrm{~Hz}$ oscillations occurring during trials of the visual discrimination task with locomotion (blue) and without locomotion (gray) ( $n=21$ neurons). $C$, The mean probability of 3-5 Hz oscillations occurring during trials of the visual discrimination task when the pupil is $>50 \%$ (red) and $<50 \%$ (gray) of full size ( $n=4$ neurons). $\boldsymbol{D}, E$, The probability of an oscillation occurring during a trial of the visual task was no different when animals were running or not running $(n=21$, WSRT, $p=0.76)$ and when the pupil was $>50 \%$ or $<50 \%$ of full size $(n=4$, WSRT, $p=0.63)$. $\boldsymbol{F}$, The average number of $3-5 \mathrm{~Hz} V_{\mathrm{m}}$ oscillations per minute occurring during locomotion (blue) and when locomotion was absent (gray) was not significantly different ( $n=21$ neurons, WSRT, $p=0.46$ ). G, The number of oscillations occurring when the pupil was $0 \%-25 \%, 25 \%-50 \%$, $50 \%-75 \%$, and $75 \%-100 \%$ of its full size was unchanged across pupil sizes ( $n=4$ neurons, one-way ANOVA, $p=0.96$ ). Error bars and shading represent SEM.

increases (Fries et al., 2008). During visually guided working memory tasks in nonhuman primates, prominent high-amplitude 4-8 Hz LFP oscillations appear in visual cortex and synchronize single-unit firing to the peaks of the oscillations during the delay period (Lee et al., 2005; Liebe et al., 2012). If coordinated subthreshold oscillations are responsible for producing these LFP and spiking patterns, their role may be to exclude processing of unattended cues during attention and task irrelevant visual information during working memory.

However, this hypothesis is challenged by our finding that $3-5$ $\mathrm{Hz} V_{\mathrm{m}}$ oscillations are provoked following visual stimulation during passive viewing. This phenomenon was independent of visual stimulus duration, disproving the hypothesis that oscillations are recruited at a fixed time following visual stimulus onset.
Although 3-5 $\mathrm{Hz} V_{\mathrm{m}}$ oscillations remotely resemble microsleep events, $3-5 \mathrm{~Hz} V_{\mathrm{m}}$ oscillations did not disrupt task performance as microsleep events do in rats (Vyazovskiy et al., 2011). Visually evoked 3-5 Hz $V_{\mathrm{m}}$ oscillation recruitment did not significantly vary with motor activities, including licking and locomotion. So, it is very unlikely that grooming, which occurred rarely in our well-trained animals, or other unmeasured motor actions played a significant role in evoking $3-5 \mathrm{~Hz} V_{\mathrm{m}}$ oscillations. Alternatively, $3-5 \mathrm{~Hz} V_{\mathrm{m}}$ oscillations could be a transient analog of alpha LFP/ EEG oscillations $(8-12 \mathrm{~Hz})$, a brain state in humans characterized by inhibition and thought to represent idling in cortical circuits (Pfurtscheller et al., 1996; Moosmann et al., 2003; Klimesch et al., 2007). But if this were the case, one would hypothesize $3-5 \mathrm{~Hz} V_{\mathrm{m}}$ oscillations to be most frequent during times 


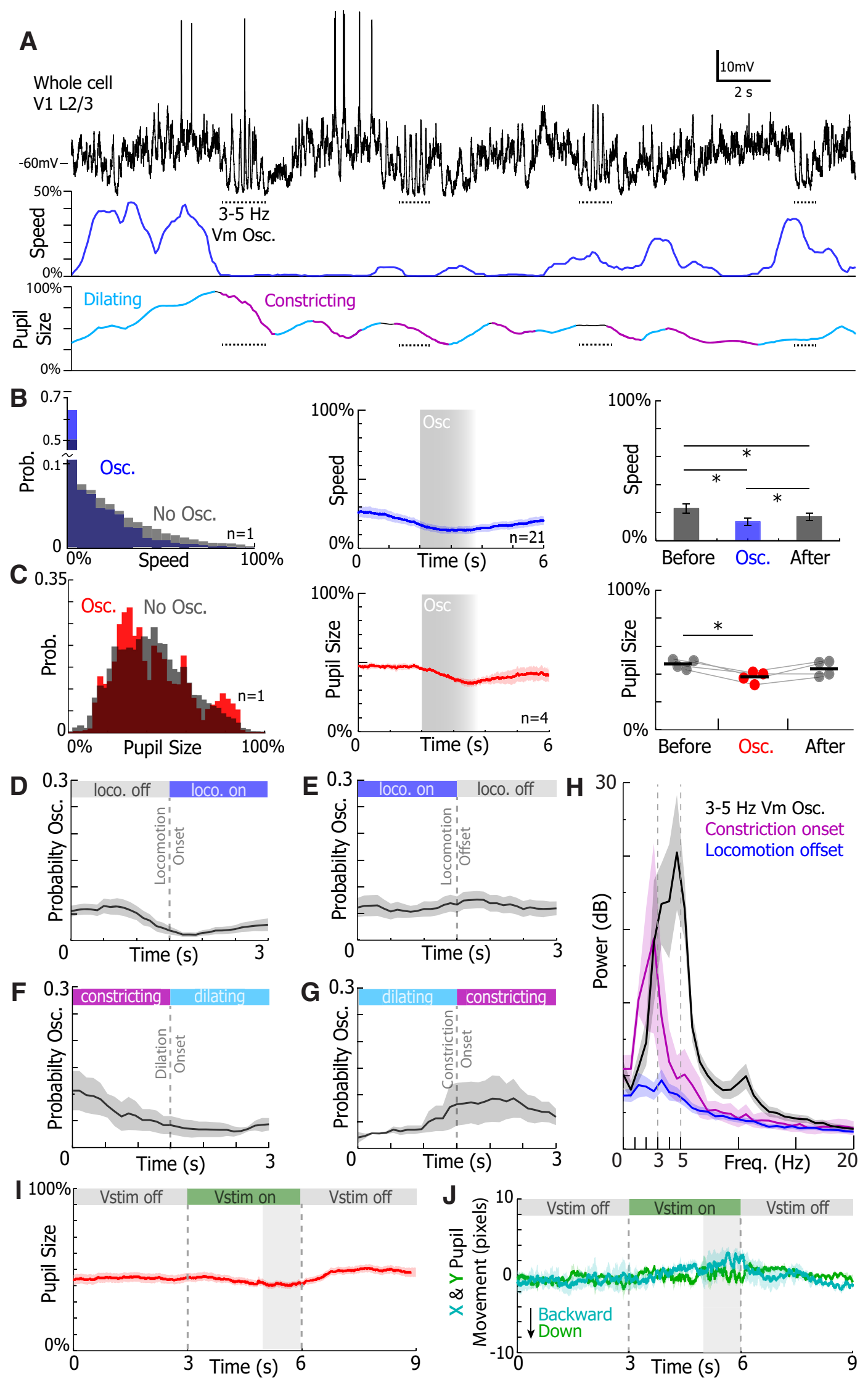

Figure 10. Oscillations are correlated with small reductions in speed and pupil size. $A$, Example $\mathrm{V} 1 \mathrm{~L} 2 / 3 \mathrm{~V}_{\mathrm{m}}$ animal speed, and pupil size traces. Dotted horizontal lines indicate $3-5 \mathrm{~Hz} V_{\mathrm{m}}$ oscillations. Periods where the pupil was detected to be dilating and constricting are marked in teal and purple, respectively. $\boldsymbol{B}, \boldsymbol{C}$, Left, Example histogram of speed and pupil size during (colored) and in the absence (gray) of $3-5 \mathrm{~Hz} V_{\mathrm{m}}$ oscillations. Middle, The oscillation triggered mean speed and pupil size. Gray box represents oscillation onset and average duration. Right, The mean speed and pupil size before, during, and after an $3-5 \mathrm{~Hz} V_{\mathrm{m}}$ oscillation. Speed was greater before and after oscillations ( $\boldsymbol{B}$, bottom, WSRT, Before vs 0scillation, $p=0.0001$, (Figure legend continues.) 
when the visual cortex is not engaged, such as during the auditory task or extended periods where visual cues were not shown to untrained animals. We observe the opposite of this in our study.

Although the differences in the timing of oscillations during active behavior and passive viewing raises several questions, it does suggest that $3-5 \mathrm{~Hz} V_{\mathrm{m}}$ oscillations are pertinent to behavior. This is reinforced by the finding that behavioral response in the visual discrimination task influences oscillation timing and recruitment. To better understand the role of $3-5 \mathrm{~Hz} V_{\mathrm{m}}$ oscillations in behavior, it will be important to understand how $3-5 \mathrm{~Hz}$ $V_{\mathrm{m}}$ oscillations affect visual perception during behavior. Specifically, if short visual stimuli $(<500 \mathrm{~ms})$ coincide completely with $3-5 \mathrm{~Hz} V_{\mathrm{m}}$ oscillations, animals may not be able perceive the stimulus to make a cued decision. If this were the case, $3-5 \mathrm{~Hz} V_{\mathrm{m}}$ oscillations coinciding with a distracting visual cue could help an animal make the correct decision. This could be accomplished with a system that triggers short visual cues when oscillations occur. In addition, our study only examined interneuron activity during oscillations observed during passive viewing. Given the effects of pupil dilation and activity on $\mathrm{SOM}^{+}$neurons, it will be important to confirm that interneurons behave similarly during $3-5 \mathrm{~Hz} V_{\mathrm{m}}$ oscillations in active behaviors (Reimer et al., 2014). As a result, many more studies will need to be completed to fully understand the role of $3-5 \mathrm{~Hz} V_{\mathrm{m}}$ oscillations in behaving animals.

The $3-5 \mathrm{~Hz} V_{\mathrm{m}}$ oscillation generation could be the result of resonant activity in the thalamocortical network. The thalamocortical loop is responsible for generating several natural and pathological oscillations, including oscillations in the $3-5 \mathrm{~Hz}$ range (Steriade et al., 1993, Destexhe and Sejnowski, 2003, Buzsáki and Draguhn, 2004). Thalamocortical neurons switch between tonic spiking and oscillatory burst firing depending on their resting membrane potential, a phenomenon largely due to low-voltage activated T-type $\mathrm{Ca}^{2+}$ channels (Jahnsen and Llinás, 1984; Contreras, 2006; Halassa, 2011). Neuromodulatory inputs, including cholinergic and monoaminergic sources, regulate the resting membrane potential of thalamic neurons to allow or block the generation of oscillations (McCormick, 1989; Steriade et al., 1993; Saper et al., 2005). Given that neuromodulatory tone can play a key role in modulating visual processing (McCormick et al., 1993; Disney et al., 2007; Chubykin et al., 2013; Pinto et al., 2013; Polack et al., 2013), it is conceivable that 3-5 Hz oscillations could be caused by a change in thalamic neuromodulation, allowing thalamocortical neurons to hyperpolarize and enter a burst state capable of generating 3-5 Hz oscillations. In support of this hypothesis, we find that $3-5 \mathrm{~Hz} V_{\mathrm{m}}$ oscillations are correlated with a small decline in pupil size, which could be indicative of reduced locus ceruleus activity and norepinephrine signaling (Aston-Jones et al., 1999; Gilzenrat et al., 2010).

\section{$\leftarrow$}

(Figure legend continued.) Before vs After, $p=0.0011,0$ scillation vs After, $p=0.0176$ ). Pupil size was greater before oscillations ( $C$, bottom, WSRT, Before vs 0scillation, $p=0.028$, Beforevs After, $p=0.79$, 0scillation vs After, $p=0.34$ ). The mean probability of evoking a $3-5 \mathrm{~Hz} \mathrm{~V}$ oscillation at locomotion onset $(\boldsymbol{D})$ and $(\boldsymbol{E})$ offset. The probability of evoking an oscillation was slightly dampened after oscillation onset (WSRT, $p=0.012$ ). The mean probability of evoking an oscillation at dilation onset $(\boldsymbol{F})$ and $(\boldsymbol{G})$ constriction onset. The probability of evoking an oscillation was no different before and after dilation onset $(n=4$, WSRT, $p=0.91)$ and constriction onset $(n=4$, WSRT, $p=0.25)$. $\boldsymbol{H}$, The mean periodogram of the $V_{\mathrm{m}}$ during $3-5 \mathrm{~Hz}$ $V_{\mathrm{m}}$ oscillation and the $1.5 \mathrm{~s}$ following constriction onset, and locomotion offset. $I$, Mean pupil size during visual cues while animals performed visual discrimination. J, The mean $x$ and $y$ movement of the pupil during visual cues while animals performed visual discrimination. Error bars and shading represent SEM. ${ }^{*} p<0.05$.
In conclusion, future studies will be needed to fully understand the cellular and network properties and behavioral significance of subthreshold 3-5 Hz oscillations. Further studies should focus on understanding how and where these oscillations are generated. In addition, it will be important to record these subthreshold oscillations in other brain areas during different behavioral tasks to understand whether they exert a similar role in sensory processing as in visual cortex and to clarify their role in during behavior.

\section{Notes}

Supplemental material for this article is available at https://github.com/ michaeleinstein/3-5-Hz/blob/master/get4hzOsc.m (code for isolating 3-5 Hz $V_{\mathrm{m}}$ oscillations). This material has not been peer reviewed.

\section{References}

Amzica F, Steriade M (1995) Short- and long-range neuronal synchronization of the slow $(<1 \mathrm{~Hz})$ cortical oscillation. J Neurophysiol 73:20-38. Medline

Aston-Jones G, Rajkowski J, Cohen J (1999) Role of locus coeruleus in attention and behavioral flexibility. Biol Psychiatry 46:1309-1320. CrossRef Medline

Bennett C, Arroyo S, Hestrin S (2013) Subthreshold mechanisms underlying state-dependent modulation of visual responses. Neuron 80:350-357. CrossRef Medline

Buzsáki G, Draguhn A (2004) Neuronal oscillations in cortical networks. Science 304:1926-1929. CrossRef Medline

Carandini M, Ferster D (1997) A tonic hyperpolarization underlying contrast adaptation in cat visual cortex. Science 276:949-952. CrossRef Medline

Cardin JA, Palmer LA, Contreras D (2008) Cellular mechanisms underlying stimulus-dependent gain modulation in primary visual cortex neurons in vivo. Neuron 59:150-160. CrossRef Medline

Chubykin AA, Roach EB, Bear MF, Shuler MG (2013) A cholinergic mechanism for reward timing within primary visual cortex. Neuron 77:723735. CrossRef Medline

Contreras D (2006) The role of T-channels in the generation of thalamocortical rhythms. CNS Neurol Disord Drug Targets 5:571-585. CrossRef Medline

Contreras D, Steriade M (1995) Cellular basis of EEG slow rhythms: a study of dynamic corticothalamic relationships. J Neurosci 15:604-622. Medline

Crochet S, Petersen CC (2006) Correlating whisker behavior with membrane potential in barrel cortex of awake mice. Nat Neurosci 9:608-610. CrossRef Medline

Destexhe A, Sejnowski TJ (2003) Interactions between membrane conductances underlying thalamocortical slow-wave oscillations. Physiol Rev 83: 1401-1453. CrossRef Medline

Destexhe A, Rudolph M, Paré D (2003) The high-conductance state of neocortical neurons in vivo. Nat Rev Neurosci 4:739-751. CrossRef Medline

Disney AA, Aoki C, Hawken MJ (2007) Gain modulation by nicotine in macaque V1. Neuron 56:701-713. CrossRef Medline

Engel AK, Fries P, Singer W (2001) Dynamic predictions: oscillations and synchrony in top-down processing. Nat Rev Neurosci 2:704-716. CrossRef Medline

Fries P, Neuenschwander S, Engel AK, Goebel R, Singer W (2001) Rapid feature selective neuronal synchronization through correlated latency shifting. Nat Neurosci 4:194-200. CrossRef Medline

Fries P, Womelsdorf T, Oostenveld R, Desimone R (2008) The effects of visual stimulation and selective visual attention on rhythmic neuronal synchronization in macaque area V4. J Neurosci 28:4823-4835. CrossRef Medline

Gilzenrat MS, Nieuwenhuis S, Jepma M, Cohen JD (2010) Pupil diameter tracks changes in control state predicted by the adaptive gain theory of locus coeruleus function. Cogn Affect Behav Neurosci 10:252-269. CrossRef Medline

Haider B, McCormick DA (2009) Rapid neocortical dynamics: cellular and network mechanisms. Neuron 62:171-189. CrossRef Medline

Halassa MM (2011) Thalamocortical dynamics of sleep: roles of purinergic neuromodulation. Semin Cell Dev Biol 22:245-251. CrossRef Medline

Jahnsen H, Llinás R (1984) Electrophysiological properties of guinea-pig 
thalamic neurones: an in vitro study. J Physiol 349:205-226. CrossRef Medline

Klimesch W, Sauseng P, Hanslmayr S (2007) EEG alpha oscillations: the inhibition-timing hypothesis. Brain Res Rev 53:63-88. CrossRef Medline

Lakatos P, Karmos G, Mehta AD, Ulbert I, Schroeder CE (2008) Entrainment of neuronal oscillations as a mechanism of attentional selection. Science 320:110-113. CrossRef Medline

Lampl I, Reichova I, Ferster D (1999) Synchronous membrane potential fluctuations in neurons of the cat visual cortex. Neuron 22:361-374. CrossRef Medline

Lee H, Simpson GV, Logothetis NK, Rainer G (2005) Phase locking of single neuron activity to theta oscillations during working memory in monkey extrastriate visual cortex. Neuron 45:147-156. CrossRef Medline

Liebe S, Hoerzer GM, Logothetis NK, Rainer G (2012) Theta coupling between V4 and prefrontal cortex predicts visual short-term memory performance. Nat Neurosci 15:456-462; S1-S2. CrossRef Medline

McCormick DA (1989) Cholinergic and noradrenergic modulation of thalamocortical processing. Trends Neurosci 12:215-221. CrossRef Medline

McCormick DA, Wang Z, Huguenard J (1993) Neurotransmitter control of neocortical neuronal activity and excitability. Cereb Cortex 3:387-398. CrossRef Medline

McGinley MJ, David SV, McCormick DA (2015) Cortical membrane potential signature of optimal states for sensory signal detection. Neuron 87:179-192. CrossRef Medline

Mitchell JF, Sundberg KA, Reynolds JH (2009) Spatial attention decorrelates intrinsic activity fluctuations in macaque area V4. Neuron 63:879888. CrossRef Medline

Moosmann M, Ritter P, Krastel I, Brink A, Thees S, Blankenburg F, Taskin B, Obrig H, Villringer A (2003) Correlates of alpha rhythm in functional magnetic resonance imaging and near infrared spectroscopy. Neuroimage 20:145-158. CrossRef Medline

Nowak LG, Sanchez-Vives MV, McCormick DA (2005) Role of synaptic and intrinsic membrane properties in short-term receptive field dynamics in cat area 17. J Neurosci 25:1866-1880. CrossRef Medline

Petersen CC, Hahn TT, Mehta M, Grinvald A, Sakmann B (2003) Interaction of sensory responses with spontaneous depolarization in layer $2 / 3$ barrel cortex. Proc Natl Acad Sci U S A 100:13638-13643. CrossRef Medline

Pfurtscheller G, Stancák A Jr, Neuper C (1996) Event-related synchronization (ERS) in the alpha band: an electrophysiological correlate of cortical idling. A review. Int J Psychophysiol 24:39-46. CrossRef Medline

Pinto L, Goard MJ, Estandian D, Xu M, Kwan AC, Lee SH, Harrison TC, Feng G, Dan Y (2013) Fast modulation of visual perception by basal forebrain cholinergic neurons. Nat Neurosci 16:1857-1863. CrossRef Medline

Polack PO, Friedman J, Golshani P (2013) Cellular mechanisms of brain state-dependent gain modulation in visual cortex. Nat Neurosci 16:13311339. CrossRef Medline

Pologruto TA, Sabatini BL, Svoboda K (2003) ScanImage: flexible software for operating laser scanning microscopes. Biomed Eng Online 2:13. CrossRef Medline

Poulet JF, Petersen CC (2008) Internal brain state regulates membrane potential synchrony in barrel cortex of behaving mice. Nature 454:881-885. CrossRef Medline

Reimer J, Froudarakis E, Cadwell CR, Yatsenko D, Denfield GH, Tolias AS (2014) Pupil fluctuations track fast switching of cortical states during quiet wakefulness. Neuron 84:355-362. CrossRef Medline

Saper CB, Scammell TE, Lu J (2005) Hypothalamic regulation of sleep and circadian rhythms. Nature 437:1257-1263. CrossRef Medline

Schneider DM, Nelson A, Mooney R (2014) A synaptic and circuit basis for corollary discharge in the auditory cortex. Nature 513:189-194. CrossRef Medline

Schroeder CE, Lakatos P (2009) Low-frequency neuronal oscillations as instruments of sensory selection. Trends Neurosci 32:9-18. CrossRef Medline

Steriade M, McCormick DA, Sejnowski TJ (1993) Thalamocortical oscillations in the sleeping and aroused brain. Science 262:679-685. CrossRef Medline

Tan AY, Chen Y, Scholl B, Seidemann E, Priebe NJ (2014) Sensory stimulation shifts visual cortex from synchronous to asynchronous states. Nature 509:226-229. CrossRef Medline

Taniguchi H (2014) Genetic dissection of GABAergic neural circuits in mouse neocortex. Front Cell Neurosci 8:8. CrossRef Medline

Vinck M, Batista-Brito R, Knoblich U, Cardin JA (2015) Arousal and locomotion make distinct contributions to cortical activity patterns and visual encoding. Neuron 86:740-754. CrossRef Medline

Vyazovskiy VV, Olcese U, Hanlon EC, Nir Y, Cirelli C, Tononi G (2011) Local sleep in awake rats. Nature 472:443-447. CrossRef Medline

Wiest MC, Nicolelis MA (2003) Behavioral detection of tactile stimuli during 7-12 Hz cortical oscillations in awake rats. Nat Neurosci 6:913-914. CrossRef Medline

Woody CD, Gruen E (1978) Characterization of electrophysiological properties of intracellularly recorded neurons in the neocortex of awake cats: a comparison of the response to injected current in spike overshoot and undershoot neurons. Brain Res 158:343-357. CrossRef Medline

Zagha E, Ge X, McCormick DA (2015) Competing neural ensembles in motor cortex gate goal-directed motor output. Neuron 88:565-577. CrossRef Medline

Zhou M, Liang F, Xiong XR, Li L, Li H, Xiao Z, Tao HW, Zhang LI (2014) Scaling down of balanced excitation and inhibition by active behavioral states in auditory cortex. Nat Neurosci 17:841-850. CrossRef Medline 